\title{
A Global Map of COVID-I9 Vaccine Acceptance Rates per Country: An Updated Concise Narrative Review
}

\author{
Malik Sallam iD ${ }^{1-3}$ \\ Mariam Al-Sanafi iD ${ }^{4,5}$ \\ Mohammed Sallam (iD ${ }^{6}$ \\ 'Department of Pathology, Microbiology \\ and Forensic Medicine, School of \\ Medicine, the University of Jordan, \\ Amman, Jordan; ${ }^{2}$ Department of Clinical \\ Laboratories and Forensic Medicine, Jordan \\ University Hospital, Amman, Jordan; \\ ${ }^{3}$ Department of Translational Medicine, \\ Faculty of Medicine, Lund University, \\ Malmö, Sweden; ${ }^{4}$ Department of Pharmacy \\ Practice, Faculty of Pharmacy, Kuwait \\ University, Kuwait City, Kuwait; \\ ${ }^{5}$ Department of Pharmaceutical Sciences, \\ Public Authority for Applied Education and \\ Training, College of Health Sciences, Safat, \\ Kuwait; ' ${ }^{6}$ Department of Pharmacy, \\ Mediclinic Welcare Hospital, Mediclinic \\ Middle East, Dubai, United Arab Emirates
}

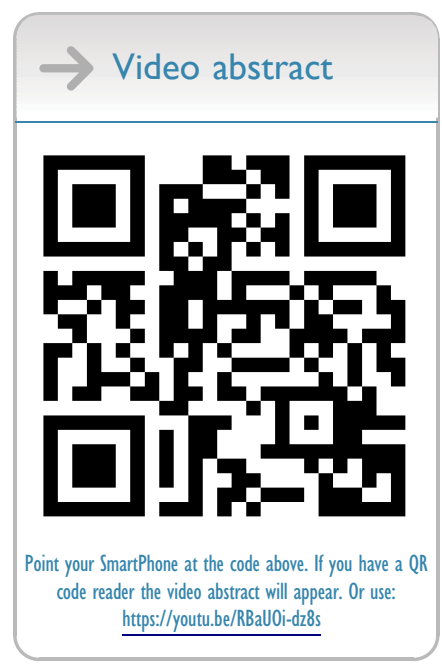

Correspondence: Malik Sallam $\mathrm{Tel}+962791845186$

Email malik.sallam@ju.edu.jo

\begin{abstract}
The delay or refusal of vaccination, which defines vaccine hesitancy, is a major challenge to successful control of COVID-19 epidemic. The huge number of publications addressing COVID-19 vaccine hesitancy necessitates periodic review to provide a concise summary of COVID-19 vaccine acceptance rates worldwide. In the current narrative review, data on COVID-19 vaccine acceptance rates were retrieved from surveys in 114 countries/ territories. In East and Southern Africa ( $n=9)$, the highest COVID-19 vaccine acceptance rate was reported in Ethiopia (92\%), while the lowest rate was reported in Zimbabwe (50\%). In West/ Central Africa $(n=13)$, the highest rate was reported in Niger $(93 \%)$, while the lowest rate was reported in Cameroon (15\%). In Asia and the Pacific $(n=16)$, the highest rates were reported in Nepal and Vietnam (97\%), while the lowest rate was reported in Hong Kong (42\%). In Eastern Europe/Central Asia $(n=7)$, the highest rates were reported in Montenegro $(69 \%)$ and Kazakhstan (64\%), while the lowest rate was reported in Russia (30\%). In Latin America and the Caribbean $(\mathrm{n}=20)$, the highest rate was reported in Mexico $(88 \%)$, while the lowest rate was reported in Haiti (43\%). In the Middle East/North Africa (MENA, $n=22$ ), the highest rate was reported in Tunisia (92\%), while the lowest rate was reported in Iraq (13\%). In Western/Central Europe and North America $(\mathrm{n}=27)$, the highest rates were reported in Canada $(91 \%)$ and Norway (89\%), while the lowest rates were reported in Cyprus and Portugal (35\%). COVID-19 vaccine acceptance rates $\geq 60 \%$ were seen in $72 / 114$ countries/territories, compared to 42 countries/territories with rates between $13 \%$ and $59 \%$. The phenomenon of COVID-19 vaccine hesitancy appeared more pronounced in the MENA, Europe and Central Asia, and Western/ Central Africa. More studies are recommended in Africa, Eastern Europe and Central Asia to address intentions of the general public to get COVID-19 vaccination.
\end{abstract}

Keywords: SARS-CoV-2, vaccine hesitance, vaccine resistance, vaccine rejection, willingness to vaccinate, intention to vaccinate

\section{Introduction}

The prevention of infectious diseases through vaccination can be considered as one of the most important achievements of modern science. ${ }^{1}$ However, the availability of vaccines and vaccination services per se does not guarantee achieving the desired effect of alleviating the burden of infectious diseases. ${ }^{2,3}$ One major challenge to vaccination success is the phenomenon of vaccine hesitancy, which can be defined as "the reluctance or rejection of getting the vaccines despite the availability of vaccination services". 4,5 Vaccine hesitancy accompanied the early days of vaccination modern inception in the 1800 s, as reviewed comprehensively by Eve Dubé et al. ${ }^{6}$ 
Vaccine hesitancy is time, place and context-specific phenomenon that can be addressed with multicomponent and dialogue-based interventions, carefully tailored according to the target population. ${ }^{4,7}$ The potential factors that can drive vaccine hesitancy are mostly related to lack of confidence in safety and effectiveness of vaccination; inconvenience (difficulty in affordability and accessibility to vaccination); and complacency (entailing low perception of disease risks). ${ }^{4,5,9}$

The manifestations of vaccine hesitancy appeared to be more pronounced amid the ongoing coronavirus disease 2019 (COVID-19) pandemic, considering the relatively rapid spread of misinformation/disinformation with embrace of conspiracy beliefs associated with the pandemic. ${ }^{10-13}$ The issue of COVID-19 vaccine hesitancy/rejection requires a special attention in the global collaborative efforts aiming to control the ongoing serious pandemic. ${ }^{14-16}$

Several vaccines based on different technologies have been approved for use to prevent severe acute respiratory syndrome coronavirus 2 (SARS-CoV-2) infection. ${ }^{17,18}$ The currently approved COVID-19 vaccines have been shown to display excellent safety and efficacy profiles in various settings. ${ }^{19,20}$ A majority of these vaccines (eg, PfizerBioNTech COVID-19 vaccine (tozinameran), Moderna COVID-19 vaccine, Oxford-AstraZeneca COVID-19 vaccine) helped to reduce the incidence and severity of SARSCoV-2 infection. ${ }^{21}$ Possible challenges to successful COVID-19 vaccination campaigns include unequal distribution globally, and continued emergence of SARS-CoV-2 lineages (variants) with immune escape capability. ${ }^{22,23}$ Furthermore, COVID-19 vaccine hesitancy continues to present a serious threat to the efforts aimed to control the ongoing pandemic. $^{24}$

A previous systematic review had investigated COVID-19 vaccine acceptance rates worldwide based on survey studies by December $2020 .^{25}$ This review showed the large scope of the problem, particularly in the Middle East and North Africa (MENA), with a lack of studies in Africa, the Caribbean and Latin America. ${ }^{25}$

In this narrative review, the aim was to provide an updated concise perspective on the status of COVID-19 vaccine acceptance rates worldwide. This objective appears crucial, considering the huge number of publications investigating COVID-19 vaccine acceptance/hesitancy from different countries/territories and regions of the world. Thus, an updated review appears necessary to describe the patterns of this phenomenon which may threaten the efforts needed to lessen the devastating effect of COVID-19 pandemic.

\section{Materials and Methods}

In this review, a total of 175 different countries/territories were classified into seven regions as follows (for convenience, this classification was based on The Joint United Nations Programme on HIV/AIDS (UNAIDS) regional classification with minor modifications; https://www. unaids.org/en/regionscountries/regions): Eastern and Southern Africa (21 countries), Western and Central Africa (25 countries), Asia and the Pacific (29 countries), Eastern Europe and Central Asia (17 countries), Latin America and the Caribbean (27 countries), Middle East and North Africa (23 countries), and Western/Central Europe and North America (33 countries, Figure 1).

Then, the search for the literature investigating COVID-19 vaccine acceptance/hesitancy rates in each country/region was based mainly on MEDLINE/PubMed and Google Scholar, besides a Google search for published reports on the review topic.

The inclusion criteria were as follows: 1) peerreviewed published articles, preprints or reports reporting the results of surveys, or research studies among the general population, health-care workers, students, or parents/ guardians, with the major aim being the investigation of COVID-19 vaccine acceptance/hesitancy; and 2) English as the publication language.

For the final assignment in the global map of COVID-19 vaccine acceptance rates per country, if multiple studies were found from a single country, the priority was given to surveys conducted at a country level (rather than a city or region). The priority was also given to surveys conducted among the general population; however, if no studies from the general population were found, then we opted to use the results of surveys conducted among healthcare workers or students.

\section{Results}

\section{Eastern and Southern Africa}

Out of 21 countries in Eastern and Southern Africa region, COVID-19 vaccine acceptance rates were found only in nine countries (Figure 2). Data were found from Ethiopia, Kenya, Malawi, Mozambique, Rwanda, South Africa, Uganda, Zambia, and Zimbabwe, while no data were found from Angola, Botswana, Comoros, Eritrea, Eswatini, Lesotho, 


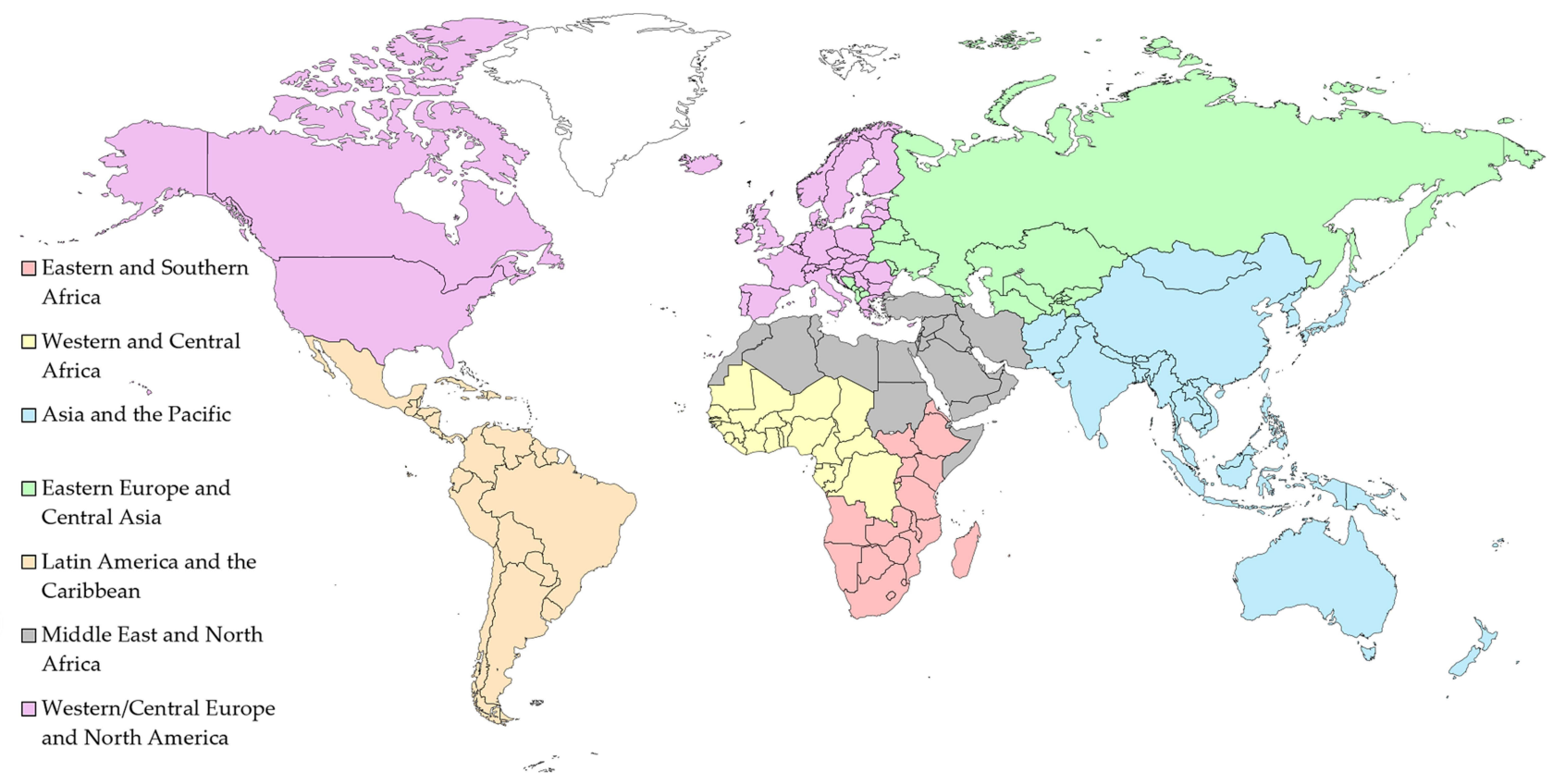

Figure I The classification of countries into seven world regions which formed the basis for this narrative review. Countries/territories in white color were not screened in the review. The map was generated in Microsoft Excel, powered by Bing, @ GeoNames, Microsoft, Navinfo, TomTom, Wikipedia. We are neutral with regard to jurisdictional claims in this map.

Madagascar, Mauritius, Namibia, Seychelles, South Sudan, and Tanzania.

\section{Ethiopia}

A comprehensive phone survey of households with 2178 participants was conducted in February 2021 at the country level. ${ }^{26}$ This study indicated a very high rate of COVID-19 vaccine acceptance (92.3\%), if vaccination was available for free. ${ }^{26}$ Another intervieweradministered questionnaire that was conducted in March 2021, among 492 participants in Gurage zone, Ethiopia, showed a lower intention to get COVID-19 vaccination (62.6\%). ${ }^{27}$ Another interviewer-administered questionnaire study with 415 participants from Sodo, south-central Ethiopia in April 2021 showed an even lower rate for COVID-19 vaccine acceptance (45.5\%). ${ }^{28}$ For healthcare workers, a self-administered questionnaire study that involved more than 400 participants in public hospitals in southwestern Ethiopia in March 2021, showed an intention to get COVID-19 vaccination among $48.4 \%$ of the participants. ${ }^{29}$ Ethiopia was part of a large multinational survey conducted by the Africa Centres for Disease Control and Prevention (Africa CDC), and this survey involved 1001 participants using telephone interviewing during September-October 2020, which reported an acceptance rate for COVID-19 vaccination of $94.0 \%{ }^{30}$

\section{Kenya}

A large phone-based survey that was conducted in February 2021, involving a total of 4136 respondents, reported an overall COVID-19 vaccine acceptance rate of 63.5\%. ${ }^{31}$ The Africa CDC survey study involved Kenya, and reported an overall COVID-19 vaccine acceptance rate of $85.0 \%$, using telephone interviewing among 1000 participants. ${ }^{30}$

\section{Malawi}

A phone-based survey was conducted during OctoberNovember 2020 and showed an overall level of COVID-19 vaccine acceptance of $82.7 \%$, as a part of a multinational study in sub-Saharan Africa, which was reported recently in a preprint. ${ }^{32}$ Another survey in the country that was part of a larger study involving 15 African countries reported similar results in Malawi (80.0\% among 1009 participants using face-to-face interviews during October-December 2020). ${ }^{30}$

\section{Mozambique}

A self-administered electronic survey was conducted in Mozambique in March 2021 and involved 1878 respondents including healthcare workers. ${ }^{33}$ This study reported an overall COVID-19 vaccine acceptance rate of $71.4 \%$, with a higher rate of $86.6 \%$ among healthcare workers and $64.8 \%$ among other respondents. ${ }^{33}$ A large study by Solís 
Country; Acceptance rate (\%); Survey date

1. Ethiopia; (92\%); February 2021

2. Kenya; (64\%); February 2021

3. Malawi; (80\%); October-December 2020

4. Mozambique; (65\%); March 2021

5. Rwanda; (85\%); October-November 2020

6. South Africa; (76\%); September-October 2020

7. Uganda; (87\%); November-December 2020

8. Zambia; (66\%); November 2020

9. Zimbabwe; (50\%); February 2021
Acceptance Rate (\%)

$0 \quad 60100$

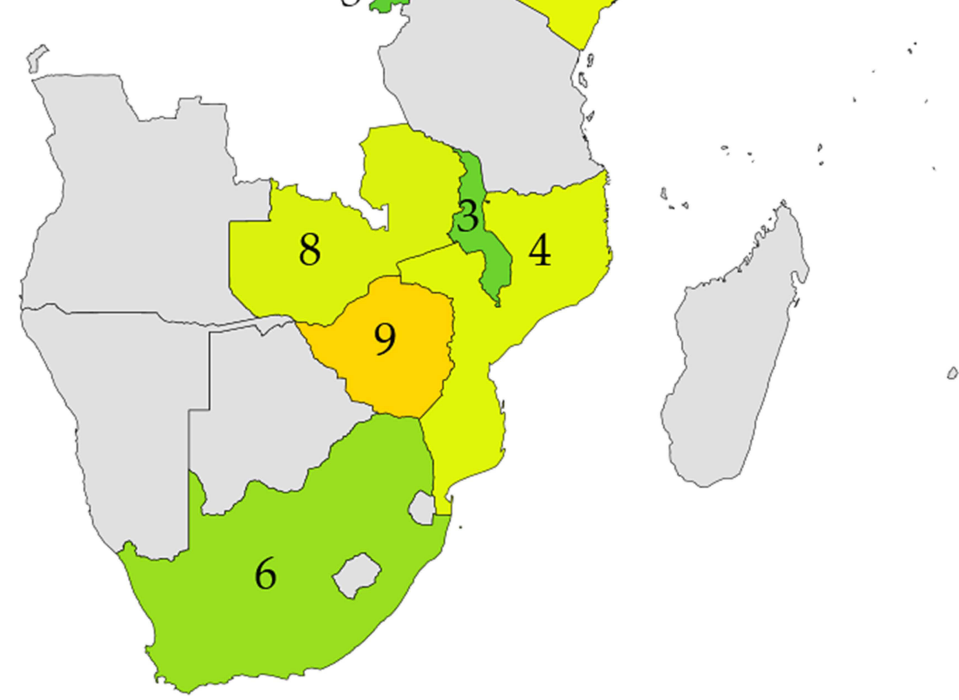

Figure 2 COVID-19 vaccine acceptance rates in countries from Eastern and Southern Africa. The included countries were numbered, with COVID-19 vaccine acceptance rates shown besides the dates of surveys. The map was generated in Microsoft Excel, powered by Bing, () GeoNames, Microsoft, Navinfo, TomTom, Wikipedia. We are neutral with regard to jurisdictional claims in this map.

Arce et al, in low- and middle-income countries, used a phone-based survey involving 862 participants from Mozambique during October-November 2020 and showed an overall COVID-19 vaccine acceptance rate of $89.1 \% .^{34}$

\section{Rwanda}

The study by Solís Arce et al involved Rwanda using a phone-based survey during October-November 2020 with 1356 participants and reported an acceptance rate for COVID-19 vaccination of $84.9 \% .{ }^{34}$

\section{South Africa}

A large multinational survey that was conducted in June 2020 reported an overall COVID-19 vaccine acceptance rate of $81.6 \%$ in South Africa. ${ }^{35}$ The Africa CDC survey was also conducted in South Africa during September-October 2020 and involved 1056 participants who were subjected to face-to-face interviews and reported COVID-19 vaccine acceptance rate of $76.0 \%{ }^{30}$ In
December 2020, a self-administered questionnaire among 1308 healthcare workers in the Eastern Cape Province of South Africa reported an overall COVID-19 vaccine acceptance rate of $90.1 \%{ }^{36}$

\section{Uganda}

The survey conducted by Africa CDC involved 1008 participants from Uganda during November-December 2020, who were surveyed through face-to-face interviews, reported an overall COVID-19 vaccine acceptance rate of $87.0 \%{ }^{30}$ The study by Solís Arce et al involved Uganda as well, with sub-national phone interviews involving 13 districts during September-December 2020, and showed $85.8 \%$ COVID-19 vaccine acceptance rate. ${ }^{34}$

\section{Zambia}

A survey among parents/guardians who brought their children for childhood vaccination in November 2020 reported an overall COVID-19 vaccine acceptance rate of $66.0 \%{ }^{37}$ 
A later online survey study among 326 undergraduate pharmacy students in the country in April 2021 showed a much lower rate of COVID-19 vaccine acceptance (24.5\%). ${ }^{38}$

\section{Zimbabwe}

The results of an online survey study were reported in a recent preprint, and this survey was conducted in February 2021 among 1168 participants who showed an acceptance rate for COVID-19 vaccination of $49.9 \% .{ }^{39}$

\section{Western and Central Africa}

Out of 25 countries in Western and Central Africa region, COVID-19 vaccine acceptance rates were found in 13 countries (Figure 3). Data were found from Benin, Burkina Faso, Cameroon, Côte d'Ivoire, Democratic Republic of the Congo (DRC), Gabon, Ghana, Liberia, Niger, Nigeria, Senegal, Sierra Leone, and Togo, while no data were found from Burundi, Cape Verde, Central African Republic, Chad, Equatorial Guinea, Gambia, Guinea, Guinea-Bissau, Mali, Mauritania, Republic of the Congo and Sao Tome and Principe.

\section{Benin}

A large survey study in Benin among other western African countries was conducted by Afrobarometer (a non-partisan, pan-African research institution conducting public attitude surveys), using face-to-face interviews in the native languages and a sample of 1200 respondents during October 2020-January 2021. ${ }^{40}$ This survey showed that the percentage of COVID-19 vaccine acceptance was $51 \%{ }^{40}$

\section{Burkina Faso}

In a large survey study about COVID-19 vaccine acceptance and hesitancy in low- and middle-income countries, a phone-based survey reported an acceptance rate for COVID-19 vaccination of $66.5 \%$ during OctoberDecember 2020 with 979 participants. ${ }^{34}$ Burkina Faso was also among the countries involved in the earlier Africa CDC survey study, with 1037 participants who had face-to-face interviews, and the overall vaccine acceptance rate was $86.0 \%$ during October-November $2020 .{ }^{30}$

\section{Cameroon}

During May-August 2020, a questionnaire was distributed in a hybrid way (in person and online) among Cameroonians

Acceptance Rate (\%) $\quad 00100$

Country; Acceptance rate (\%); Survey date

1. Benin; (51\%); October 2020-January 2021

2. Burkina Faso; (67\%); October-December 2020

3. Cameroon; (15\%); May-August 2020

4. Côte d'Ivoire; (71\%); September-November 2020

5. DRC; (56\%); August-September 2020

6. Gabon; (67\%); September-December 2020

7. Ghana; (51\%); February 2021

8. Liberia; (34\%); October 2020-January 2021

9. Niger; (93\%); September 2020

10. Nigeria; (76\%); November-December 2020

11. Senegal; (21\%); October 2020-January 2021

12. Sierra Leone; (88\%); October 2020-January 2021

13. Togo; (50\%); October 2020-January 2021

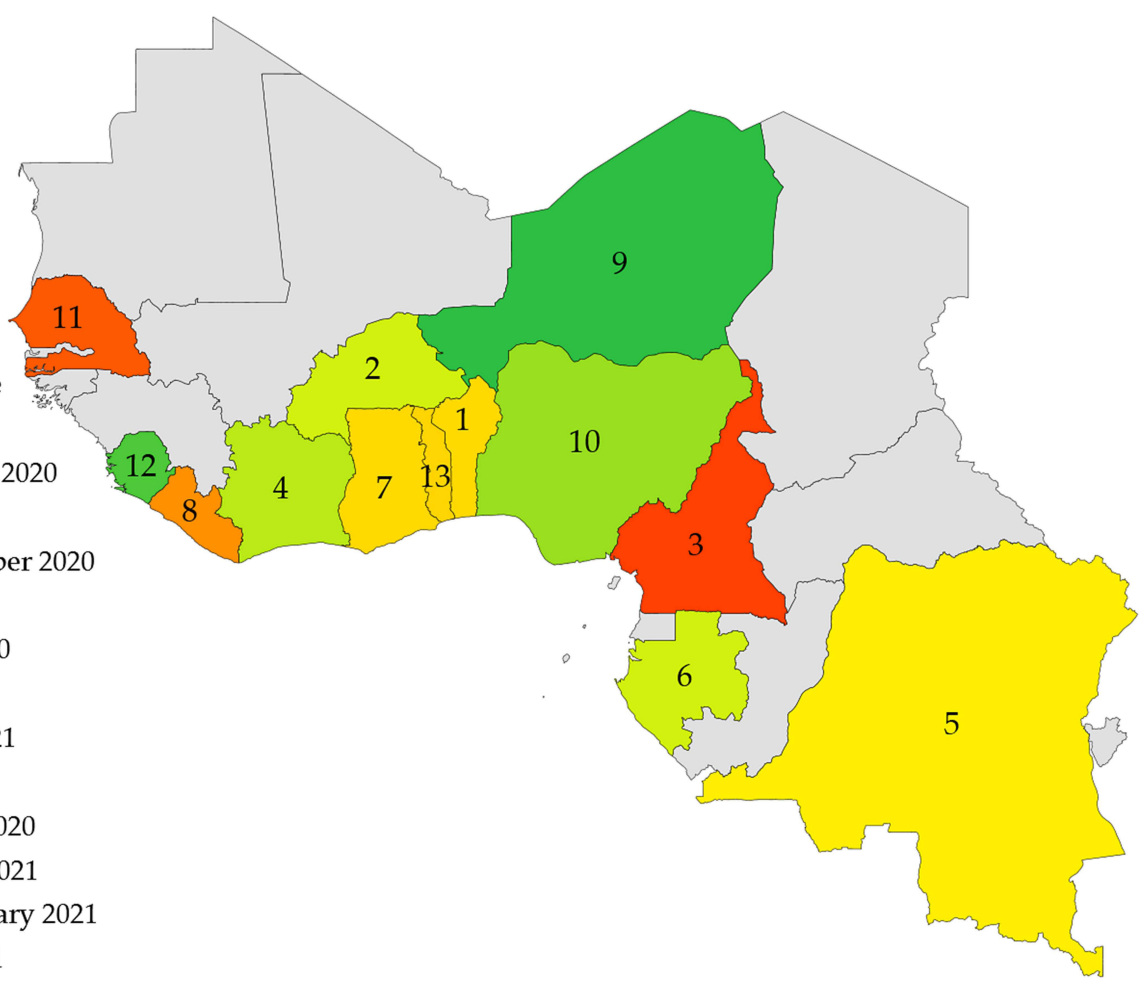

Figure 3 COVID-19 vaccine acceptance rates in countries from Western and Central Africa. The included countries were numbered, with COVID-I9 vaccine acceptance rates shown besides the dates of surveys; DRC: Democratic Republic Of The Congo. The map was generated in Microsoft Excel, powered by Bing, $\bigodot$ GeoNames, Microsoft, Navinfo, TomTom, Wikipedia. We are neutral with regard to jurisdictional claims in this map. 
inside and outside the country. Among 2512 participants, COVID-19 vaccine acceptance rate was $15.4 \%{ }^{41}$

\section{Côte d'Ivoire}

As a part of a survey conducted by the Africa CDC, faceto-face interviewing among 1039 participants from the country during September-November 2020 revealed an acceptance rate for COVID-19 vaccination of $71.0 \%{ }^{30}$

\section{Democratic Republic of the Congo}

An online survey that was conducted in AugustSeptember 2020, and involved 4131 respondents, showed that the overall COVID-19 vaccine acceptance rate was $55.9 \%$ in DRC. ${ }^{42}$ The acceptance rate was slightly higher in the Africa CDC survey, which involved 1007 participants in DRC using face-to-face interviews during September-October 2020 that reported an acceptance rate of $59.0 \%$ for COVID-19 vaccination. ${ }^{30}$

\section{Gabon}

The country was part of the Africa CDC study, which involved 1112 participants who had face-to-face interviews during September-December 2020 and reported COVID-19 vaccine acceptance rate of $67.0 \%{ }^{30}$

\section{Ghana}

A cross-sectional online survey was conducted among 1000 Ghanaian respondents during OctoberDecember 2020 and showed an acceptance rate of 54.1\% for COVID-19 vaccination. ${ }^{43}$ A recent online survey that was conducted in February 2021 and involved 2345 adult Ghanaians showed a slightly lower rate for COVID-19 vaccine acceptance of $51 \% .{ }^{44}$

\section{Liberia}

The large survey by Afrobarometer involved Liberia during October 2020-January 2021 and showed an overall COVID-19 vaccine acceptance rate of $34 \%{ }^{40}$

\section{Niger}

As a part of the survey conducted by the Africa CDC, faceto-face interviewing among 1173 participants from the country was conducted in September 2020, which showed an acceptance rate for COVID-19 vaccination of $93 \%{ }^{30}$

\section{Nigeria}

The Africa CDC survey involved Nigeria with face-to-face interviewing of 1172 participants from the country during September-October 2020, which showed an overall acceptance rate of $73 \%$ for COVID-19 vaccination. ${ }^{30}$ Another study from Nigeria among healthcare workers using a self-administered questionnaire was conducted in October 2020 and showed an acceptance rate of $55.5 \%$ for COVID-19 vaccination. ${ }^{45}$ Another study was conducted in December 2020 and involved e-survey with 401 participants in the Delta state, which showed an overall COVID19 vaccine acceptance rate of $48.6 \%{ }^{46}$ Nigeria was also part of the phone survey study conducted during November-December 2020 by Solís Arce et al, which showed an acceptance rate of $76.2 \%$ for COVID-19 vaccination among the general public in the country. ${ }^{34}$

\section{Senegal}

The Africa CDC survey study involved Senegal with faceto-face interviewing among 1010 participants from the country during October-November 2020, and this survey showed an overall acceptance rate of $65 \%$ for COVID-19 vaccination. ${ }^{30}$ The vaccine acceptance rate was much lower in the Afrobarometer survey that involved 1200 respondents during October 2020-January 2021 which reported a COVID-19 vaccine acceptance rate of only $21 \%{ }^{40}$

\section{Sierra Leone}

In the multinational large survey study by Solís Arce et al, a phone-based survey during October 2020-January 2021, reported an acceptance rate for COVID-19 vaccination of $87.9 \%$ in the country. ${ }^{34}$

\section{Togo}

The large study by Afrobarometer involved Togo during October 2020-January 2021 and reported an overall COVID-19 vaccine acceptance rate of $50 \% .{ }^{40}$

\section{Asia and the Pacific}

Out of 29 countries/territories in this region, COVID-19 vaccine acceptance rates were found in 16 countries/territories (Figure 4). Data were found from Afghanistan, Australia, Bangladesh, China, Hong Kong, India, Indonesia, Japan, Malaysia, Nepal, New Zealand, Pakistan, Philippines, South Korea, Taiwan, and Vietnam, while no data were found from Bhutan, Brunei, Cambodia, North Korea, Fiji, Laos, Maldives, Mongolia, Myanmar, Papua New Guinea, Singapore, Sri Lanka and Thailand.

\section{Afghanistan}

An online survey during December 2020-January 2021 was conducted among the general public in the country, 


\section{Acceptance Rate (\%)}

Country; Acceptance rate (\%); Survey date

1. Afghanistan; (63\%); December 2020-January 2021

2. Australia; (59\%); August 2020

3. Bangladesh; (61\%); January-February 2021

4. China; (82\%); January-February 2021

5. Hong Kong; (42\%); December 2020-January 2021

6. India; (79\%); January 2021

7. Indonesia; (65\%); September 2020

8. Japan; (56\%); February 2021

9. Malaysia; (83\%); December 2020

10. Nepal; (97\%); December 2020

11. New Zealand; (70\%); March 2021

12. Pakistan; (72\%); January-February 2021

13. Philippines; (63\%); January 2021

14. South Korea; (77\%); May-June 2021

15. Taiwan; (53\%); October 2020

16. Vietnam; (97\%); October-December 2020

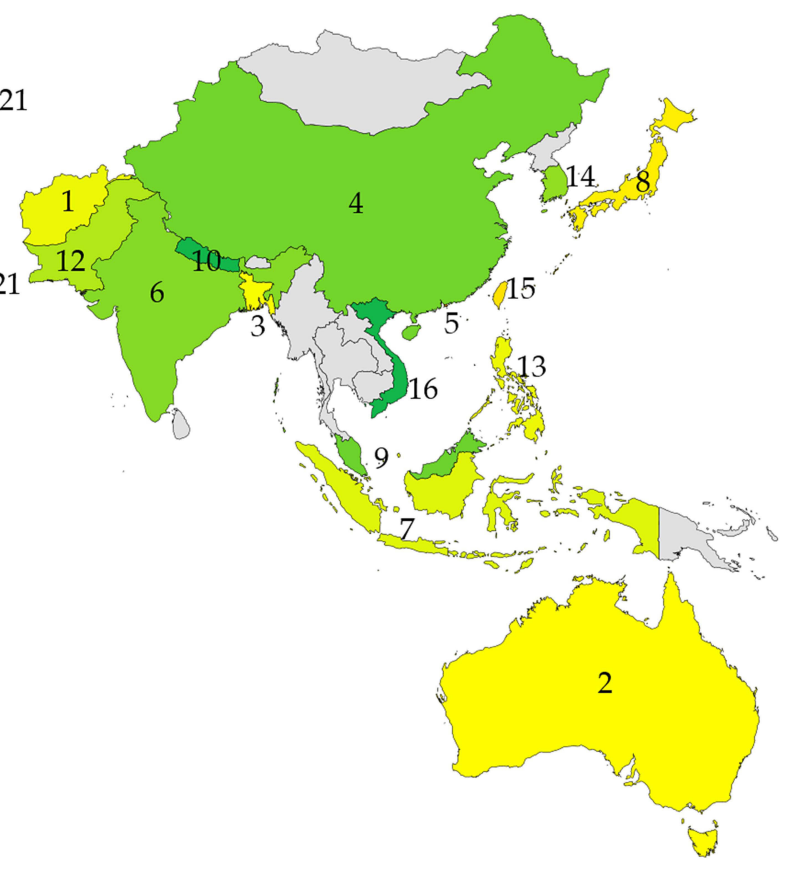

Figure 4 COVID-19 vaccine acceptance rates in countries/territories from Asia and the Pacific. The included countries/territories were numbered, with COVID-I9 vaccine acceptance rates shown besides the dates of surveys. The map was generated in Microsoft Excel, powered by Bing, ( GeoNames, Microsoft, Navinfo, TomTom, Wikipedia. We are neutral with regard to jurisdictional claims in this map.

with 806 participants. ${ }^{47}$ This study showed an overall COVID-19 vaccine acceptance rate of $63.2 \%$.

\section{Australia}

In August 2020, data from 3061 adults in Australia (collected mostly online) showed an acceptance rate for COVID-19 vaccination of 59\%. ${ }^{48}$ Another online survey study showed that COVID-19 vaccine acceptance rate was $72 \%$ in Sydney and $78 \%$ in Melbourne during JulySeptember 2020. ${ }^{49}$ An earlier study among Australian parents in June 2020 showed that the acceptance rate for COVID-19 vaccination was $75.8 \%$ with a $10 \%$ declining rate in the same group compared to an earlier study. ${ }^{50,51}$

\section{Bangladesh}

An online-based survey study involving 605 respondents that was conducted during January-February 2021 showed an overall rate for COVID-19 vaccine acceptance of $61.2 \% .^{52}$ Another study from the country using face-to-face interviews and involved 1134 participants from the general population in January 2021 showed an overall COVID-19 vaccine acceptance rate of $67.5 \%{ }^{53}$ In a larger study that used both online and face-to-face interviews and was conducted during JanuaryFebruary 2021 involving 4175 respondents, the COVID-19 vaccine acceptance rate was $60.5 \% .^{54}$ A study from Bangladesh among healthcare workers in January 2021 showed that COVID-19 vaccine acceptance rate was only $43.8 \%$ among this group. ${ }^{55}$

\section{China}

The recent surveys in the country showed the following: an online survey conducted in January 2021 revealed that COVID-19 vaccine acceptance rate among healthcare workers $(\mathrm{n}=1329)$ was $77.0 \%$, while the vaccine acceptance rate among general population $(n=1251)$ was $56.2 \%{ }^{56}$ A large study involving both China and the US, with a total of 5375 participants from China during January-February 2021 showed that COVID-19 vaccine acceptance rate was $82.0 \%$ in the country. ${ }^{57}$ An online survey study conducted in January 2021 with 9508 respondents revealed a lower vaccine acceptance rate of $67.1 \%{ }^{58}$

\section{Hong Kong}

A telephone-based survey conducted during December 2020January 2021 and involving 1255 adults indicated that 
COVID-19 vaccine acceptance rate was $42 \% .{ }^{59}$ Another study involving two surveys among the same 2047 participants during the first and third waves of the local epidemic showed a declining rate for COVID-19 vaccine acceptance from $44.2 \%$ in February 2020 to $34.8 \%$ in August/ September $2020{ }^{60}$

\section{India}

The study by Solís Arce et al involved a sub-national sample from India with data collected using phone interviews during June 2020-January 2021, which revealed an acceptance rate of $84.3 \%$ for COVID-19 vaccination. ${ }^{34}$ In January 2021, an online survey among 2032 participants showed that $78.6 \%$ expressed willingness to receive COVID-19 vaccination. ${ }^{61}$ A recent study in March 2021, involving 1294 participants recruited online, showed an acceptance rate of $83.6 \%$ for COVID-19 vaccination. ${ }^{62}$ Another online survey among 721 healthcare workers in January 2021 showed that $79.3 \%$ were willing to get COVID-19 vaccination. ${ }^{63}$

\section{Indonesia}

An early study during March-April 2020 by Harapan et al among 1359 participants showed an acceptance rate of 93.3\% for an effective COVID-19 vaccine. ${ }^{64}$ However, this rate dropped to only $65 \%$ in a tremendous survey conducted by the Ministry of Health, and the Indonesian Technical Advisory Group on Immunization, and was supported by the UNICEF and the World Health Organization (WHO), in September 2020 involving 115,000 people. ${ }^{65}$ A study conducted during September-October 2020 with 779 respondents in Bali Province showed an acceptance rate of $60.8 \%$ for COVID-19 vaccination. ${ }^{66}$

\section{Japan}

A large web-based survey took place in February 2021, involving 30,053 Japanese adults aged 20 years or older reported an overall COVID-19 vaccine acceptance rate of 56.1\%. ${ }^{67}$ An earlier study in September 2020 showed an acceptance rate of $65.7 \%$ with 1100 participants, while another study in January 2021 with 2956 participants reported an overall acceptance rate of $62.1 \%$ for COVID-19 vaccination. ${ }^{68,69}$ Another recent study (February 2021) showed that the acceptance rate for COVID-19 vaccination was only $47 \%{ }^{70}$

\section{Malaysia}

A web-based survey conducted in December 2020 with 1406 respondents showed that $64.5 \%$ were willing to get vaccinated against COVID-19. ${ }^{71}$ Another study conducted later on in December 2020, using an online survey with 1411 respondents showed a higher COVID-19 vaccine acceptance rate of $83.3 \%{ }^{72}$

\section{Nepal}

The study by Solís Arce et al involved a sub-national sample from the country with data collected using phone interviews during December 2020, which showed an acceptance rate of $96.6 \%$ for COVID-19 vaccination. ${ }^{34}$

\section{New Zealand}

An early online survey study from the country in July 2020 involving 1040 participants showed an acceptance rate of $74 \%$ for COVID-19 vaccination. ${ }^{73}$ A later web-based survey study in March 2021 with 1284 participants showed an overall COVID-19 vaccine acceptance rate of $70 \%{ }^{74}$

\section{Pakistan}

An online survey study conducted during JanuaryFebruary 2021, with 1778 participants showed an overall COVID-19 vaccine acceptance rate of $72 \%{ }^{75}$ An earlier online study conducted during September-October 2020 with 883 respondents showed a similar acceptance rate of $70.8 \%$ for COVID-19 vaccination. ${ }^{76}$ The acceptance rates were also close to those in the study by Solís Arce et al that used phone interviews in a sub-national sample $(76.1 \%$ during July-September 2020, that declined to $66.5 \%$ during September-October 2020). ${ }^{34}$ The acceptance rate for COVID-19 vaccination in Pakistan was also similar among healthcare workers in an online survey with 5237 respondents during December 2020-February 2021, which showed an acceptance rate of $70.2 \%{ }^{77}$

\section{Philippines}

A recent preprint by Caple et al reported the initial results of an online survey conducted in January 2021 that involved 7193 respondents, which showed an overall rate for COVID-19 vaccine acceptance of $62.5 \%{ }^{78}$

\section{South Korea}

A recent questionnaire survey conducted during MayJune 2021 among parents/guardians in South Korea and involving 226 participants reported an overall COVID-19 vaccine acceptance rate of $76.5 \% .^{79}$ An earlier global study by de Figueiredo and Larson, that was conducted during October-December 2020 involved 1103 participants from the country has shown an acceptance rate of $86.6 \%$ for COVID- 19 vaccination. ${ }^{80}$ 


\section{Taiwan}

A telephone-based survey was conducted in October 2020, which involved 1077 respondents, and showed an overall rate of $52.7 \%$ willingness to receive COVID-19 vaccination. $^{81}$

\section{Vietnam}

An email-based online survey study involving 398 students in Ho Chi Minh City showed an acceptance rate of $83.4 \%$ for COVID-19 vaccination. ${ }^{82}$ The earlier global study by de Figueiredo and Larson during October-December 2020 involved 599 participants from Vietnam and showed an acceptance rate of $96.8 \%$ for COVID-19 vaccination. ${ }^{80}$

\section{Eastern Europe and Central Asia}

Out of 17 countries in Eastern Europe and Central Asia region, COVID-19 vaccine acceptance rates were found only in 7 countries, 2 of which had survey studies among healthcare workers (nurses) and nursing students, while the remaining 5 studies involved the general population (Figure 5). Data on COVID-19 vaccine acceptance rates were found from Albania, Kazakhstan, Kosovo, Kyrgyzstan, Montenegro, Russia and Ukraine, while no data were found from Armenia, Azerbaijan, Belarus, Bosnia and Herzegovina, Georgia, Moldova, Tajikistan, Macedonia, Turkmenistan, and Uzbekistan.

\section{Albania}

A web-based questionnaire involving nurses in five European countries was conducted in January 2021, and this study showed that the intention of Albanian nurses to get COVID-19 vaccination if safe and effective was $46.3 \%{ }^{83}$ Another multinational European web survey study involving seven countries (during December 2020-January 2021), investigated COVID-19 vaccine acceptance among nursing students, and the results among Albanian students were lower compared to the first study among nurses (102 of 313 Albanian students, 32.6\%) completely or somewhat agreed to accept a safe and effective COVID-19 vaccine. ${ }^{84}$

$$
\text { Acceptance Rate (\%) } \quad 0 \quad 60100
$$

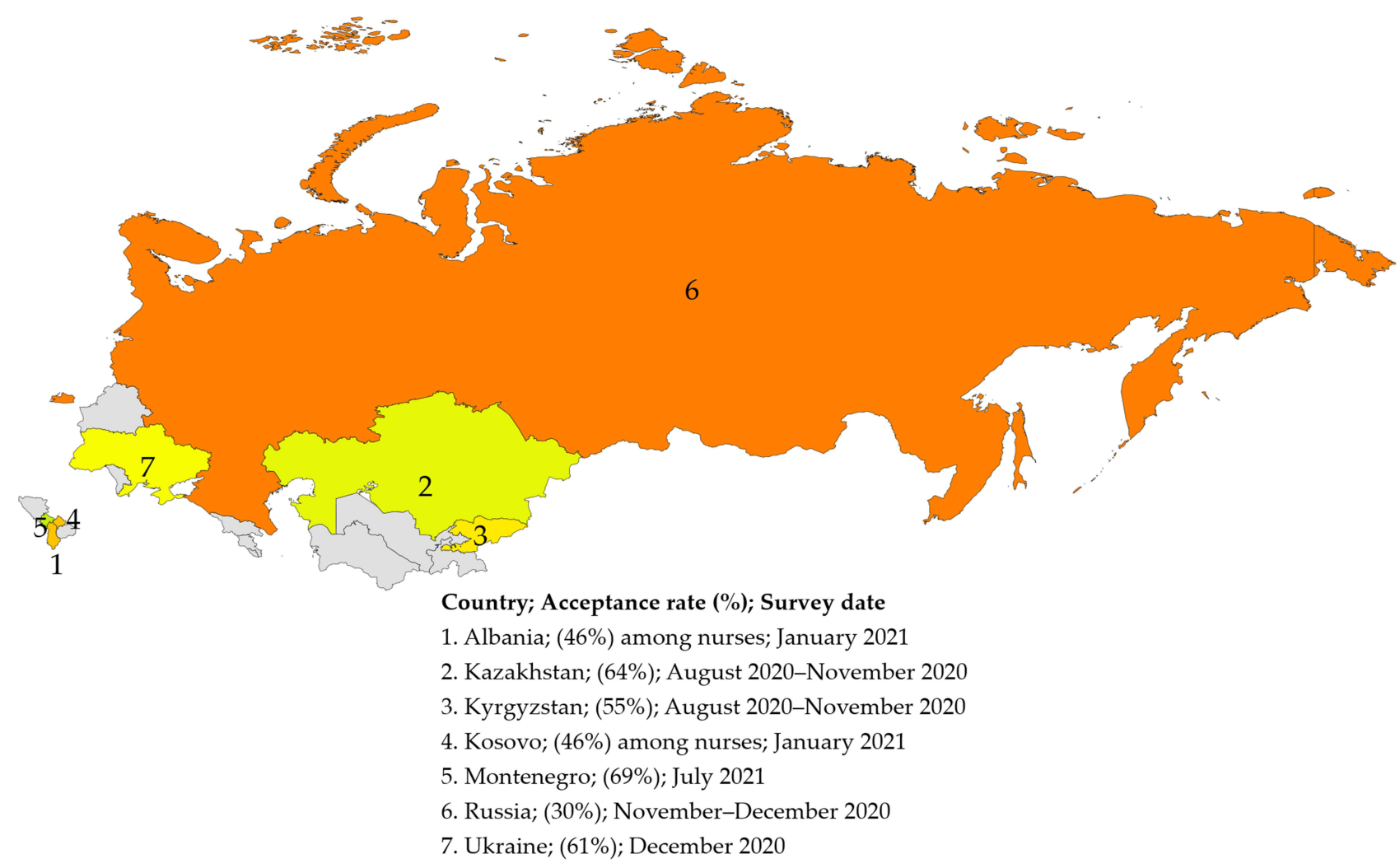

Figure 5 COVID-19 vaccine acceptance rates in countries/territories from Eastern Europe and Central Asia. The included countries/territories were numbered, with COVID-19 vaccine acceptance rates shown besides the dates of surveys. The map was generated in Microsoft Excel, powered by Bing, (C) GeoNames, Microsoft, Navinfo, TomTom, Wikipedia. We are neutral with regard to jurisdictional claims in this map. 


\section{Kazakhstan}

A web-based questionnaire was conducted during August 2020-November 2020 through e-mail invitations to students and staff of Nazarbayev University and local hospitals, which showed that 264 out of 417 respondents would get COVID-19 vaccination (63.9\%) ${ }^{85}$

\section{Kyrgyzstan}

A joint survey between the Ministry of Health and Social Development of the Kyrgyz Republic with the WHO was conducted through computer-assisted telephone interviewing. This survey involved 1000 individuals in Kyrgyzstan and was conducted in three phases during December 2020-February 2021, showed that about 55\% of the participants had a strong or some willingness to accept COVID-19 vaccination. ${ }^{86}$

\section{Kosovo}

A web-based questionnaire involving nurses in five European countries was conducted in January 2021, and this study showed that the intention of nurses from Kosovo to get COVID-19 vaccination if safe and effective was 46.2\%. ${ }^{83}$ A multinational European study among nursing students showed that 393 of 1020 nursing students from Kosovo (38.5\%) completely or somewhat agreed to accept a safe and effective COVID-19 vaccine. ${ }^{84}$

\section{Montenegro}

Using phone interviewing among adults (aged 18 years or older) in Montenegro, an opinion poll was conducted by Ipsos in July 2021 with a total of 830 respondents, and showed that among those who were not vaccinated $(57 \%$ of the total sample), $45 \%$ were planning to get COVID- 19 vaccination, $35 \%$ were resistant and $19 \%$ were hesitant. ${ }^{87}$ In the same survey, $43 \%$ of the respondents stated that they have been vaccinated, with an overall percentage of $69 \%$ of the respondents who either got vaccinated or showed willingness to get vaccinated. ${ }^{87}$

\section{Russia}

In a large survey study regarding COVID-19 vaccine acceptance and hesitancy in low- and middle-income countries, an online-based survey was conducted during November-December 2020, which reported an acceptance rate for COVID-19 vaccination in Russia of $30.4 \%{ }^{34}$ This low rate was observed in earlier surveys by Van D. Tran et al (during SeptemberNovember 2020), and Lazarus et al (in June 2020) which showed the declining COVID-19 vaccine acceptance rates of $41.7 \%$ and $54.9 \%$, respectively. ${ }^{88,89}$

\section{Ukraine}

In a letter to the editor by Matiashova et al that cited a survey of the sociological group "Rating", the COVID-19 vaccine acceptance in Ukraine was $55 \%$ if the vaccine is provided for free, and the willingness to pay for the vaccine was $35 \% .{ }^{90}$ The rate of $55 \%$ was slightly lower than the vaccine acceptance rate reported by the RECOVER social science team, which reported an acceptance rate for COVID-19 vaccination in Ukraine of $61 \%$ involving 1000 respondents that were surveyed in December $2020 .{ }^{91}$

\section{Latin America and the Caribbean}

Out of 27 countries/territories in Latin America and the Caribbean, COVID-19 vaccine acceptance rates were found in 20 countries/territories (Figure 6). Data were found from Argentina, Bolivia, Brazil, Chile, Colombia, Costa Rica, Dominican Republic, Ecuador, El Salvador, Guatemala, Haiti, Honduras, Mexico, Nicaragua, Panama, Paraguay, Peru, Puerto Rico, Uruguay, and Venezuela, while no data were found from Barbados, Belize, Cuba, Guyana, Jamaica, Suriname, and Trinidad and Tobago.

A large comprehensive cross-sectional analysis of a database collected by the University of Maryland and Facebook, was conducted by Urrunaga-Pastor et al, which investigated COVID-19 vaccine intentions, perceptions and hesitancy across Latin America and the Caribbean. ${ }^{92}$ The study involved participants aged 18 and over during January-February 2021. This study will form the basis for reporting COVID-19 vaccine acceptance in Latin America and the Caribbean in this review as follows:

The study by Urrunaga-Pastor et al involved 33,282 participants from Argentina, with COVID-19 vaccine acceptance rate of $71.7 \%$; 9486 participants from Bolivia with vaccine acceptance rate of $71.0 \% ; 162,763$ participants from Brazil, with vaccine acceptance rate of $83.1 \%$; 18,441 participants from Chile, with vaccine acceptance rate of $74.4 \%$; 32,607 participants from Colombia, with vaccine acceptance rate of $77.3 \%$; 5383 participants from Costa Rica, with vaccine acceptance rate of $84.1 \%$; 3712 participants from Dominican Republic, with vaccine acceptance rate of $65.8 \%$; 11,548 participants from Ecuador, with vaccine acceptance rate of $69.3 \%$; 4802 participants from El Salvador, with vaccine acceptance rate of $79.3 \%$; 4746 participants from Guatemala, with vaccine acceptance rate of 


\section{Acceptance Rate \\ $0 \quad 60100$}

\section{Country; Acceptance rate (\%)}

1. Argentina; $(72 \%)$

2. Bolivia; $(71 \%)$

3. Brazil; $(83 \%)$

4. Chile; (74\%)

5. Colombia; $(77 \%)$

6. Costa Rica; $(84 \%)$

7. Dominican; $(66 \%)$

8. Ecuador; (69\%)

9. El Salvador; $(79 \%)$

10. Guatemala; $(80 \%)$

11. Haiti; (43\%)

12. Honduras; (81\%)

13. Mexico; (88\%)

14. Nicaragua; (78\%)

15. Panama; (80\%)

16. Paraguay; $(65 \%)$

17. Peru; $(75 \%)$

18. Puerto Rico; (85\%)

19. Uruguay; (66\%)

20. Venezuela; $(69 \%)$
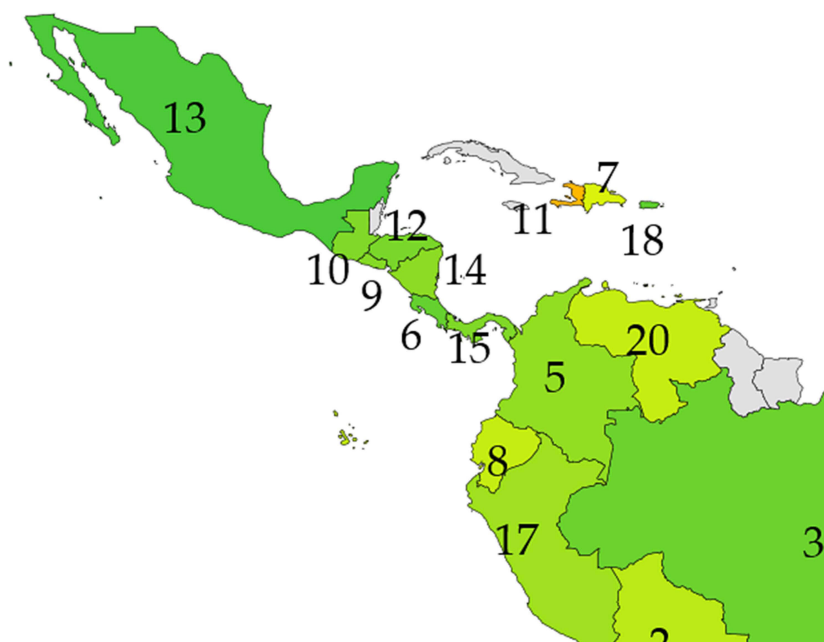

3

Figure 6 COVID-19 vaccine acceptance rates in countries/territories from Latin America and the Caribbean. All data were collected from the study by Urrunaga-Pastor et al. ${ }^{92}$ The included countries/territories were numbered, with COVID-19 vaccine acceptance rates. All surveys were conducted during January-February 202I. The map was generated in Microsoft Excel, powered by Bing, @ GeoNames, Microsoft, Navinfo, TomTom, Wikipedia. We are neutral with regard to jurisdictional claims in this map.

$79.7 \% ; 272$ participants from Haiti, with vaccine acceptance rate of $43.2 \%$; 3842 participants from Honduras, with vaccine acceptance rate of $80.5 \% ; 133,607$ participants from Mexico, with vaccine acceptance rate of $88.4 \%$; 2442 participants from Nicaragua, with vaccine acceptance rate of $77.9 \%$; 2712 participants from Panama, with vaccine acceptance rate of $80.2 \%$; 3091 participants from Paraguay, with vaccine acceptance rate of $64.6 \% ; 17,162$ participants from Peru, with vaccine acceptance rate of $74.9 \% ; 7148$ participants from Puerto Rico with vaccine acceptance rate of $85.0 \% ; 7622$ participants from Uruguay, with vaccine acceptance rate of $65.9 \%$; and 7853 participants from Venezuela, with vaccine acceptance rate of $68.8 \%{ }^{92}$

Selected additional studies from the region included a preprint reporting the results of a multinational study involving Facebook users, which pointed to COVID-19 vaccine acceptance rate of about $75 \%$ in Argentina as of March 2021. ${ }^{93}$ An earlier study from Brazil (SeptemberOctober 2020) involving 2771 participants reported a higher vaccine acceptance rate of $74.3 \%{ }^{94}$

\section{Middle East and North Africa}

Out of 23 countries/territories in the MENA region, COVID-19 vaccine acceptance rates were found in 22 countries/territories (Figure 7). Data were found from Algeria, Bahrain, Egypt, Iraq, Iran, Israel, Jordan, Kuwait, Lebanon, Libya, Morocco, Oman, Palestine, Qatar, Saudi Arabia, Somalia, Sudan, Syria, Tunisia, Turkey, United Arab Emirates (UAE), and Yemen, while no data were found from Djibouti. 


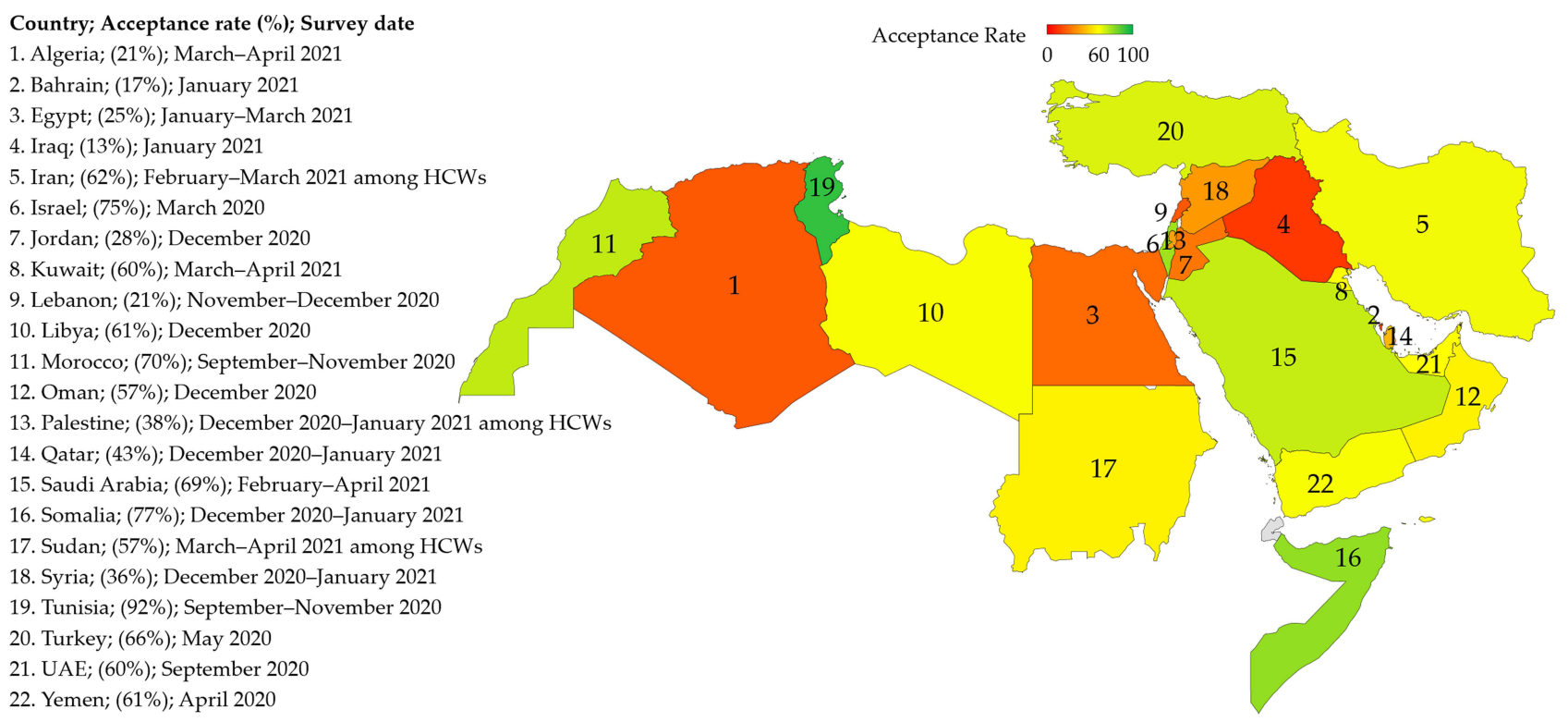

Figure 7 COVID-19 vaccine acceptance rates in countries/territories from the Middle East and North Africa. The included countries/territories were numbered, with COVID-19 vaccine acceptance rates shown besides the dates of surveys; HCWs: Healthcare workers; UAE: United Arab Emirates. The map was generated in Microsoft Excel, powered by Bing, (C) GeoNames, Microsoft, Navinfo, TomTom, Wikipedia. We are neutral with regard to jurisdictional claims in this map.

\section{Algeria}

A recent preprint reported the results of an online survey conducted during March-April 2021 among the general public in the country, with 1019 participants, which showed a willingness to get COVID-19 vaccines at a rate of $21 \%{ }^{95}$

\section{Bahrain}

A large-scale survey study in the Arab countries was conducted in January 2021, which involved Bahrain with 115 participants and the results displayed an acceptance rate for COVID-19 vaccination of $16.5 \%{ }^{96}$

\section{Egypt}

The most recent online survey study from Egypt was conducted during April-May 2021, with 871 participants showed an unusually high acceptance rate for COVID-19 vaccination (88\%), compared to previous studies in the country involving healthcare workers $(21 \%$ acceptance rate during December 2020 to January 2021; 26\% acceptance rate in January 2021), and the general public (acceptance rate of only $8 \%$ in January 2021) ${ }^{96-99}$ A recent nationwide online survey study during January-March 2021 with 1011 participants showed a COVID-19 vaccine acceptance rate of $25 \%{ }^{100}$

\section{Iraq}

The large-scale survey study in January 2021 involved Iraq with 586 participants and reported a COVID-19 vaccine acceptance rate of $13.3 \% .^{96}$

\section{Iran}

A recent preprint reported that results of a national survey among healthcare workers ( $\mathrm{n}=3536)$ during FebruaryMarch 2021 showed an overall COVID-19 vaccine acceptance of $62.1 \%{ }^{101}$

\section{Israel}

An early study in March 2020, involving 1112 participants from the general population showed an overall COVID-19 vaccine acceptance rate of $75 \% .{ }^{102}$

\section{Jordan}

Three online survey studies showed a declining rate of COVID-19 vaccine acceptance from $37.4 \%$ in November 2020 (3100 participants), to $28.4 \%$ in December 2020 (2173 participants), and reaching 13.2\% (7020 participants from the general population), and 34.9\% (1106 university students) in January 2021..$^{96,103-105}$

\section{Kuwait}

A recent survey study among the general public was conducted during March-April 2021 with 4147 respondents, which showed an overall COVID-19 vaccine acceptance rate of $59.8 \% .{ }^{106}$ Another recent survey among healthcare workers in the country showed a higher rate for COVID-19 vaccine acceptance (83.3\%) in March 2021 with 1019 participants. ${ }^{107}$ 


\section{Lebanon}

A survey study involving 579 respondents from the country was conducted during November-December 2020 showed that COVID-19 vaccine acceptance rate was $21.4 \% .{ }^{108}$

\section{Libya}

A large survey study among the general population and healthcare workers in the country was conducted in December 2020, with 11,120 participants from the general population, 1752 medical students, 1394 medical doctors, and 821 paramedics or nurses. ${ }^{109}$ The results showed that COVID-19 vaccine acceptance rate was $60.9 \%$ among the general population, $61.1 \%$ among medical students, $57.8 \%$ among medical doctors and $60.8 \%$ among nurses and paramedics. ${ }^{109}$

\section{Morocco}

The study by Africa CDC involved Morocco, with telephone interviewing of 1000 participants during September-November 2020, and this survey reported an overall COVID-19 vaccine acceptance rate of $70 \% .{ }^{30}$

\section{Oman}

A comprehensive survey involving telephone interviewing with 3000 participants was conducted in the country in December 2020, which showed 56.8\% COVID-19 vaccine acceptance rate. ${ }^{110}$

\section{Palestine}

A study among healthcare workers during December 2020-January 2021, with 1159 respondents showed that the intention to get vaccinated among the study group was $37.8 \% .^{111}$

\section{Qatar}

A phone-based interview study was conducted with a total of 1038 respondents during December 2020 January 2021, showed an acceptance rate of $42.7 \%$ for COVID-19 vaccination. ${ }^{112}$

\section{Saudi Arabia}

In a recent survey study during February-April 2021 that involved 1935 participants, $46.9 \%$ reported their intention to receive the COVID-19 vaccine, with $22.4 \%$ who received the vaccine, $9.5 \%$ who were resistant, and $21.2 \%$ who were hesitant resulting in an overall vaccine acceptance rate of $69.3 \% .{ }^{113}$ Another recent survey (March-April 2021) among healthcare workers in Saudi Arabia, which involved 390 respondents, reported an acceptance rate of $77.8 \%$ for COVID-19 vaccination. ${ }^{114}$

\section{Somalia}

An online survey study involving 4543 respondents was conducted in the country during December 2020January 2021 and reported an overall COVID-19 vaccine acceptance rate of $76.8 \%{ }^{115}$

\section{Sudan}

A web-based survey that was conducted during MarchApril 2021, with 576 healthcare workers in Sudan, reported that $57 \%$ were willing to get vaccinated against COVID-19. ${ }^{116}$

\section{Syria}

An online survey was conducted in the country during December 2020-January 2021, that involved a total of 3402 adults, had reported an acceptance rate of $35.9 \%$ for COVID-19 vaccination. ${ }^{117}$

\section{Tunisia}

The study by Africa CDC involved Tunisia, with telephone interviewing of 1000 participants during September-November 2020, and this study reported an overall COVID-19 vaccine acceptance rate of $92 \%$ in the country. ${ }^{30}$

\section{Turkey}

An early online study in May 2020, that involved 3936 participants in Turkey, showed an overall COVID-19 vaccine acceptance rate of $66 \%{ }^{118}$ The rate was higher $(84.6 \%)$ in a later study (in December 2020) that involved healthcare workers. ${ }^{119}$

\section{United Arab Emirates (UAE)}

An online survey study was conducted in September 2020 among 2705 participants in the country, with COVID-19 vaccine acceptance rate of $60.1 \% .{ }^{120}$

\section{Yemen}

A preprint that reported the results of an online survey conducted in April 2020 among 484 participants showed an acceptance rate of $61.2 \%$ for free COVID-19 vaccines. $^{121}$

\section{Western/Central Europe and North America}

Out of 33 countries in Western/Central Europe and North America region, COVID-19 vaccine acceptance rates were found in 27 countries (Figures 8 and 9). Data were found from Austria, Belgium, Bulgaria, Canada, Croatia, Cyprus, Czech Republic, Denmark, 
Acceptance Rate (\%)

$0 \quad 60100$

\section{Country; Acceptance rate (\%); Survey date}

1. Canada; (91\%); December 2020-February 2021

2. United States; (66\%); October-December 2020

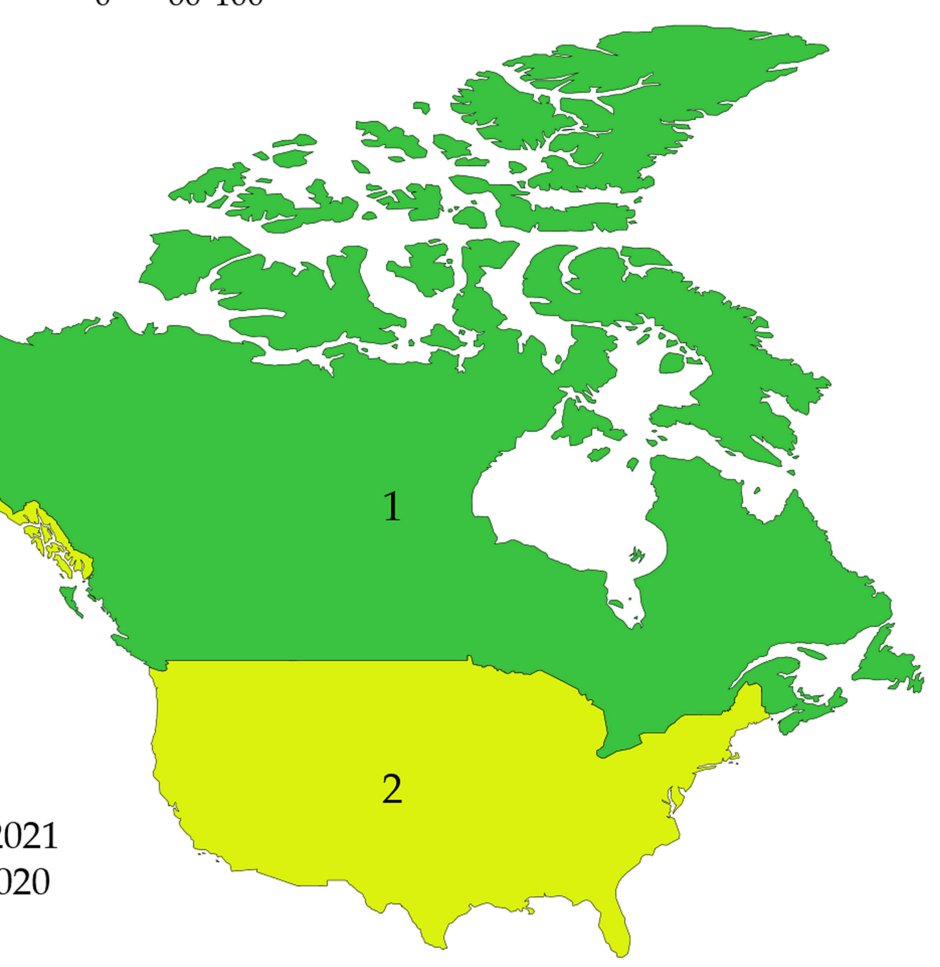

Figure 8 COVID-19 vaccine acceptance rates in North America. The map was generated in Microsoft Excel, powered by Bing, @ GeoNames, Microsoft, Navinfo, TomTom, Wikipedia. We are neutral with regard to jurisdictional claims in this map.

$$
\text { Acceptance Rate (\%) } \quad 60100
$$

Country; Acceptance rate (\%); Survey date 1. Austria; (55); February-March 2021

2. Belgium; (73); October 2020

3. Bulgaria; (49); June 2021

4. Croatia; (42); October-December 2020

5. Cyprus; (35); December 2020 among HCWs

6. Czech Republic; (73); April-June 2021 among University students

7. Denmark; (83); September 2020-February 2021

8. Finland; (74); April 2021

9. France; (47); September 2020-February 2021

10. Germany; (60); September 2020-February 2021

11. Greece; (58); April-May 2020

12. Hungary; (47); September 2020-February: 2021
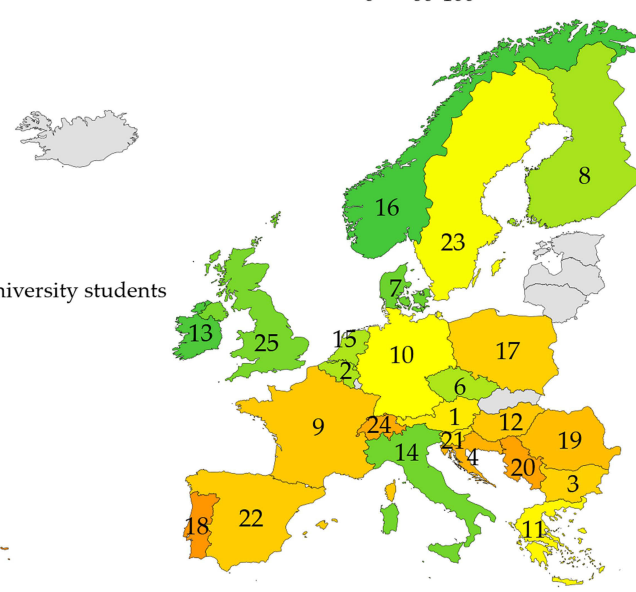

Country; Acceptance rate (\%); Survey date

13. Ireland; (88); January 2021

14. Italy; (82); December 2020

15. Netherlands; (73); April 2020

16. Norway; (89); January-February 2021

17. Poland; (51); March 2021

18. Portugal; (35); September 2020-January 2021

19. Romania; (45); December 2020

20. Serbia; (38); October-December 2020

21. Slovenia; (53); October-December 2020

22. Spain; (48); December 2020

23. Sweden; (61); September 2020-February 2021

24. Switzerland; (40); December 2020 among HCWs

25. UK; (81); October-December 2020

5

Figure 9 COVID-19 vaccine acceptance rates in countries from Central and Western Europe. The included countries were numbered, with COVID-I9 vaccine acceptance rates shown besides the dates of surveys; HCWs: Healthcare workers; UK: United Kingdom. The map was generated in Microsoft Excel, powered by Bing, (C) GeoNames, Microsoft, Navinfo, TomTom, Wikipedia. We are neutral with regard to jurisdictional claims in this map.

Finland, France, Germany, Greece, Hungary, Ireland, Italy, the Netherlands, Norway, Poland, Portugal, Romania, Serbia, Slovenia, Spain, Sweden,
Switzerland, the United Kingdom (UK), and the US, while no data were found from Estonia, Iceland, Latvia, Lithuania, Luxembourg, and Slovakia. 


\section{Austria}

An online survey that was conducted during FebruaryMarch 2021 among the general public in the country, with 1350 respondents, showed an overall rate of $55 \%$ participants who were willing to get COVID-19 vaccination. ${ }^{122}$

\section{Belgium}

An early study conducted in October 2020, with 2060

Belgians showed an acceptance rate of $73 \%$ for COVID-19 vaccination. ${ }^{123}$

\section{Bulgaria}

A preprint reporting the results of an online survey in eight European countries reported a rate of $49.1 \%$ for COVID19 vaccine acceptance in Bulgaria in June 2021. ${ }^{124}$

\section{Canada}

A nationally representative online survey was conducted during December 2020 through February 2021, with a total of 14,621 respondents, and this survey reported that $91 \%$ had intention to get vaccinated against COVID$19 .^{125}$

\section{Croatia}

A large exploratory study (during OctoberDecember 2020) that investigated the global intent to accept COVID-19 vaccination involved Croatia with 519 participants, and this study showed an acceptance rate of $41.5 \%$ for COVID-19 vaccination in the country. ${ }^{80}$

\section{Cyprus}

An online survey study among healthcare workers was conducted in December 2020, with 1220 participants, and it showed an acceptance rate of $34.9 \%$ for COVID19 vaccination. ${ }^{126}$

\section{Czech Republic}

A recent study involving 1351 university students during April-June 2021 showed an overall acceptance rate for COVID-19 vaccination of $73.3 \% .^{127}$

\section{Denmark}

A study involving eight European countries with participants from Denmark during September 2020 February 2021 with 2765 participants showed an acceptance rate of $83 \%$ for COVID-19 vaccination. ${ }^{128}$

\section{Finland}

A recent study from the country reported a COVID-19 vaccine acceptance rate of $74 \%$ in April 2021. ${ }^{129}$

\section{France}

A study involving eight European countries with participants from France during September 2020-February 2021 with 2090 participants from the country showed an acceptance rate of $47 \%$ for COVID-19 vaccination. ${ }^{128}$ An early survey conducted during June-July 2020 among 1942 adults in the country showed a higher vaccine acceptance rate of 71.8\%. ${ }^{130}$ Another earlier survey (in April 2020) in the country involving 5018 participants from the general population reported an overall COVID-19 vaccine acceptance rate of $76 \%{ }^{131}$

\section{Germany}

A study involving eight European countries with participants from Germany during September 2020February 2021 with 2380 participants from the country showed that COVID-19 vaccine acceptance rate was $60 \% .{ }^{128}$ An online survey conducted in February 2021 among 4500 healthcare workers in Germany showed a higher rate for COVID-19 vaccine acceptance $(91.7 \%)^{132}$

\section{Greece}

An online survey among the general population in Greece that was conducted during April-May 2020, with 1004 respondents showed an intention for vaccination against COVID-19 at a rate of $57.7 \%{ }^{133}$

\section{Hungary}

A study involving eight European countries with participants from Hungary during September 2020February 2021, with 1814 participants from the country showed an acceptance rate of $47 \%$ for COVID-19 vaccination. ${ }^{128}$

\section{Ireland}

In January 2021, a study involving 1600 participants showed an acceptance rate for COVID-19 vaccination of $88.2 \%{ }^{134}$

Italy

An online survey study among 7605 respondents from the general adult population in Italy in December 2020 showed that $81.9 \%$ were inclined to get vaccinated against COVID-19. ${ }^{135}$

\section{Netherlands}

An early European survey (in April 2020) involving 1000 participants from the country showed an overall COVID19 vaccine acceptance rate of $73 \%{ }^{136}$ 


\section{Norway}

A recent survey study that included 4571 participants and was conducted during January-February 2021 showed an overall rate for COVID-19 vaccine acceptance of $89 \%{ }^{137}$

\section{Poland}

A recent survey study conducted in March 2021 that included 885 respondents showed an overall COVID-19 vaccine acceptance rate of $50.8 \% .{ }^{138}$

\section{Portugal}

A study during September 2020-January 2021 with 1943 individuals showed an overall COVID-19 vaccine acceptance rate of $35.3 \%{ }^{139}$

\section{Romania}

An online survey study conducted in October 2020, with 247 adults showed that $21.9 \%$ expressed total acceptance for COVID-19 vaccination. ${ }^{140}$ Another online survey that was conducted in December 2020, with 432 participants showed $45.4 \%$ intention to get vaccinated against COVID19 among the participants. ${ }^{141}$

\section{Serbia}

The same large exploratory study by de Figueiredo and Larson that was conducted during OctoberDecember 2020 and investigated the global intent to accept COVID-19 vaccination involved Serbia with 501 participants and it showed an acceptance rate of $37.8 \%$ for COVID-19 vaccination. ${ }^{80}$

\section{Slovenia}

The same study by de Figueiredo and Larson involved Slovenia with 800 participants and it showed an acceptance rate of $53.3 \%$ for COVID-19 vaccination. ${ }^{80}$

\section{Spain}

An online survey study that was conducted in December 2020, with 2501 participants, showed an acceptance rate for COVID-19 vaccination of $48.3 \%$ in the country. ${ }^{142}$

\section{Sweden}

A study involving eight European countries with participants from Sweden during September 2020-February 2021 with 2149 participants showed an acceptance rate of $61 \%$ for COVID-19 vaccination in Sweden. ${ }^{128}$

\section{Switzerland}

A recent preprint reported the results of a web-based survey among 3793 healthcare workers in December 2020 showed that $39.8 \%$ were willingness to accept COVID-19 vaccination. ${ }^{143}$

\section{The United Kingdom (UK)}

The same large exploratory study conducted during October-December 2020 by de Figueiredo and Larson that investigated the global intent to accept COVID-19 vaccination, involved the UK with 1000 participants who showed an acceptance rate of $80.5 \%$ for COVID-19 vaccination. ${ }^{80} \mathrm{An}$ earlier survey among 1500 participants surveyed in July 2020 showed that $64 \%$ of the participants reported being very likely to be vaccinated against COVID-19. ${ }^{144}$ A recent study reported the results of different surveys in the UK among other countries, conducted between March and August 2020, and the surveys from the UK showed that vaccine acceptance rates ranged between $73.0 \%$ and $80.4 \% .{ }^{145}$ A study from Scotland among 1433 participants in August 2020 showed an acceptance rate of $77.5 \%$ for COVID-19 vaccination. ${ }^{146}$

\section{The United States (US)}

In a nationally representative survey, the self-reported likelihood of getting a COVID-19 vaccine declined from $74 \%$ in early April 2020 to $56 \%$ in early December $2020 .{ }^{147}$ The same large exploratory study during OctoberDecember 2020 by de Figueiredo and Larson that investigated the global intent to accept COVID-19 vaccination, involved the US with 800 participants and it showed an acceptance rate of $65.7 \%{ }^{80}$ Among 2978 respondents, in a nationwide study conducted during May 2020 and January 2021, 81.1\% of the participants were likely to receive the vaccine. ${ }^{148}$

\section{The Potential Gaps in Knowledge Regarding COVID-I9 Vaccine Acceptance Worldwide}

The global rates of COVID-19 vaccine acceptance are shown in Figure 10. The regions where COVID-19 vaccine acceptance levels below $60 \%$ predominates over those $\geq 60 \%$ were Eastern Europe and Central Asia, West and Central Africa, the MENA and Western/Central Europe (Figure 11).

Regions where less than $50 \%$ of the countries having estimates on COVID-19 vaccine acceptance using survey studies included Eastern Europe and Central Asia (41.2\%) and East and Southern Africa (42.9\%).

\section{Discussion}

The current narrative review can be viewed as an updated and concise description of COVID-19 vaccine acceptance 


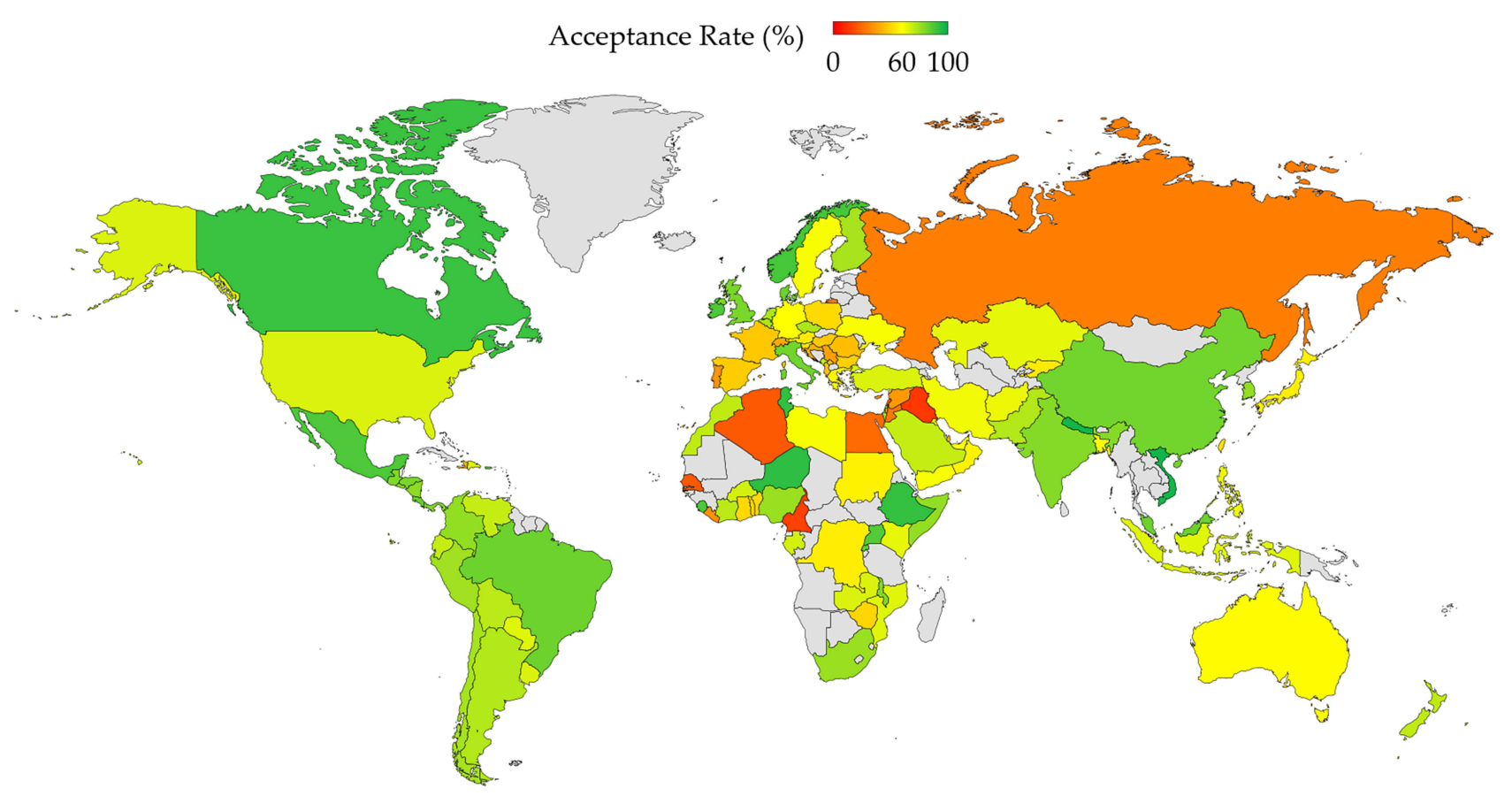

Figure 10 The global rates of COVID-19 vaccine acceptance. The map was generated in Microsoft Excel, powered by Bing, (C GeoNames, Microsoft, Navinfo, TomTom, Wikipedia. We are neutral with regard to jurisdictional claims in this map.

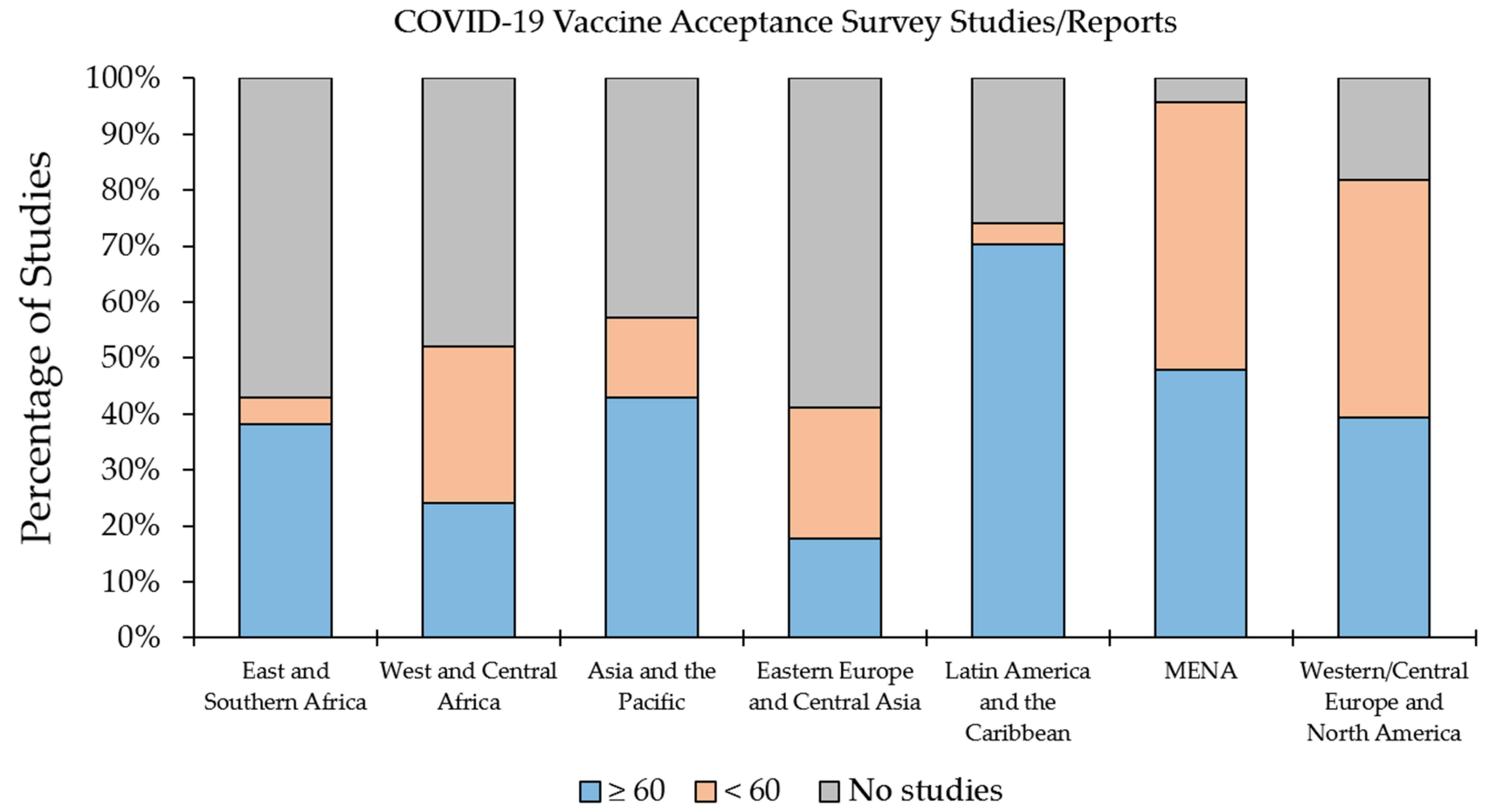

Figure II The percentage of studies on COVID-19 vaccine acceptance among different countries in different world region. Abbreviation: MENA, Middle East and North Africa.

rates among the majority of countries/territories worldwide.

The major issues that necessitate continuous assessment of COVID-19 vaccine acceptance include the increasing evidence of waning immunity against SARS-CoV-2, accompanied by continuous emergence of viral variants (lineages), some of which may display immune escape from the currently available vaccine formulas. ${ }^{149-154}$ 
The results of this review indicated a wide variability in willingness to get COVID-19 vaccination in different countries globally. Nevertheless, certain patterns were observed as follows: First, reports on COVID-19 vaccine acceptance/hesitancy in African countries were rarely found by the end of last year. ${ }^{25}$ This review showed the growing number of publications and reports from the region with higher rates of COVID-19 vaccine acceptance in East and Southern Africa compared to Western and Central part of the continent. High rates of COVID-19 vaccine hesitancy were found particularly in Cameroon (15\%), Senegal (21\%), and Liberia (34\%). This was mainly attributed to low levels of trust in foreign institutions and pharmaceutical companies. ${ }^{41}$ The results also indicated the need for more studies from Africa addressing COVID-19 vaccine hesitancy, as gaps in information still exist in several African countries (eg, Angola, Chad, Republic of Congo, Mali, Mauritania, Namibia, Tanzania).

Second, in Asia and the Pacific region, generally high rates of COVID-19 vaccine acceptance were found in a majority of countries. This was previously linked to relatively high levels of trust in governments, and the generally high level of COVID-19 vaccine acceptance in Asian countries was also found in more recent studies. ${ }^{89,155,156}$ However, high rates of COVID-19 vaccine hesitancy were reported in Hong Kong, Taiwan and Japan, and this can be explained by the growing concerns regarding vaccine safety, due to accelerated vaccine development, besides the spread of negative news about COVID-19 vaccines. $^{60,70} \mathrm{~A}$ relatively high level of COVID-19 vaccine hesitancy was also reported in a recent study from India, with only $59 \%$ of the respondents inclined to get the vaccination. ${ }^{157}$ This emphasizes the continuous need for assessment of COVID-19 vaccine hesitancy mainly in countries with suboptimal coverage of vaccination.

Third, a concerning result was the high rates of COVID-19 vaccine hesitancy and the presence of knowledge gaps in several countries from Eastern Europe and Central Asia. A recent perspective article on vaccine hesitancy in the region suggested the need to address the concerns of caregivers and healthcare professionals, and to reinforce public trust in healthcare providers. ${ }^{158}$

Fourth, in Latin America and the Caribbean, COVID-19 vaccine acceptance rates were generally high (14/20 countries with $>70 \%$ COVID-19 vaccine acceptance rates). The comprehensive publication by Urrunaga-Pastor et al attributed such a result to the observation that the region is among the most heavily afflicted regions by the pandemic globally, with high rates of death per capita in the region, which in turn might have led to lower levels of complacency. ${ }^{92,159}$ The generally favorable attitude towards COVID-19 vaccine acceptance might have contributed to generally high vaccine coverage observed in the Caribbean. ${ }^{160}$

Fifth, several MENA region countries reported very low levels of COVID-19 vaccine acceptance (with six countries ranked among the top 10 countries with regard to COVID-19 vaccine hesitancy among the countries included in this review). This result was previously reported in an earlier systematic review that reported COVID-19 vaccine acceptance rates by the end of December 2020 and is further supported by the observations made in this review. ${ }^{25}$ Such high levels of COVID-19 vaccine hesitancy can be linked to high levels of distrust in healthcare providers and concerns about vaccine safety besides the high embrace of conspiracy beliefs in some countries of the region..$^{13,96,104,105,161}$ Despite that, a few countries in the region managed to achieve vaccination coverage rates that were among highest globally (eg, Israel, UAE), which was attributed to the massive efforts to build vaccine confidence. ${ }^{162,163}$

Finally, high rates of COVID-19 vaccine hesitancy were reported in Western and Central Europe. The picture was better in some European countries (Ireland, Italy, Norway and UK) and in Canada and the US. A recent publication regarding COVID-19 vaccine hesitancy in the US, showed that the geospatial disparity of vaccine hesitancy is highly correlated with socio-economics covariates (eg, ethnicity, income, etc), and the authors advocated the role of policymakers, community groups, and faith leaders in increasing public trust to reduce vaccine hesitancy. ${ }^{164}$ Vaccine hesitancy in some European countries were linked to concerns about safety and efficacy besides the speed with which these vaccines were developed. ${ }^{138,139,142}$

The conspicuous pattern of declining rates of COVID-19 vaccine acceptance observed in different countries in this review (Australia, Ethiopia, France, Japan and Jordan), can appear antithetical considering the accumulating evidence of safety and efficacy of the currently approved COVID-19 vaccines. ${ }^{165,166}$ However, a study involving eight European countries showed increasing levels of vaccine acceptance over time. ${ }^{128}$ Thus, the complex nature of COVID-19 vaccine hesitancy must be addressed at a deeper level considering the major factors linked to such phenomenon (demographic, geopolitical, religious and cultural factors). ${ }^{167}$ 


\section{Strengths and Limitations}

To the best of our knowledge, the current narrative review represents the most detailed update on a majority of publications and relevant preprints and reports that investigated COVID-19 vaccine acceptance rates in different countries, territories and regions worldwide.

Limitations include potential sampling bias in several studies that formed the basis of the current review, besides the different time points during which these surveys were conducted which can complicate the interpretation of their results, particularly in relation to the timing of COVID-19 vaccination rollout in each country. One major limitation is related to the different definitions used to delineate COVID-19 vaccine acceptance, where some studies used yes/no definition, yes/ unsure (undecided)/no (undecided), very likely, somewhat likely, etc, besides different survey item phrasing.

An additional limitation is the swift pace of growth in literature addressing COVID-19 vaccine hesitancy, which may have resulted in missing a few recent publications. For example, our analysis missed two recent studies among the general public in Mongolia and Sri Lanka, which was likely the result of timing of these publications. ${ }^{168,169}$ These studies reported COVID-19 vaccine acceptance rates of $68.3 \%$ in Mongolia, with the survey distributed in FebruaryMarch 2021, and 86.0\% among the general public in Sri Lanka.

The current narrative review focused on reporting the acceptance rates for COVID-19 vaccination per country/territory, and the investigation of the predictors of acceptability was out of scope of this review; however, such factors can be found in other recently published and comprehensive reviews addressing the issue. ${ }^{170-173}$

\section{Conclusion}

In the current narrative review, a concise description of COVID-19 vaccine acceptance rates is presented based on surveys from 114 different countries/territories worldwide. Countries with the highest rates of COVID-19 vaccine acceptance included Nepal and Vietnam (97\%), Niger (93\%), Ethiopia and Tunisia (92\%), and Canada (91), while the lowest rates were reported in Iraq (13\%), Cameroon (15\%), Bahrain (17\%), Algeria, Lebanon and Senegal (21\%). The phenomenon of COVID-19 vaccine hesitancy appeared more pronounced in some world regions (the MENA region, Central Europe and Central Asia, and Western and Central Africa). More studies are recommended in Africa, Eastern Europe and Central Asia, considering the presence of large gaps in information regarding COVID-19 vaccine hesitancy in these regions. Low COVID-19 vaccination rates that might be related to vaccine hesitancy in some regions can cause serious public health threats considering the potential emergence of novel variants with vaccine escape potential.

\section{Acknowledgments}

We are deeply grateful for Ms Huda Eid for her invaluable help. We would also like to thank Dr Khaled Al-Salahat, Ms Rabaa Athamneh and Ms Hanan Hasan for their kind assistance.

\section{Funding}

This research received no external funding.

\section{Disclosure}

The authors report no conflicts of interest in this work.

\section{References}

1. Greenwood B. The contribution of vaccination to global health: past, present and future. Philos Trans R Soc Lond B Biol Sci. 2014;369(1645):20130433. doi:10.1098/rstb.2013.0433

2. Gostin LO, Hodge JG, Bloom BR, et al. The public health crisis of underimmunisation: a global plan of action. Lancet Infect Dis. 2020;20(1):e11-e16. doi:10.1016/s1473-3099(19)30558-4

3. Larson HJ. The biggest pandemic risk? Viral misinformation. Nature. 2018;562(7727):309. doi:10.1038/d41586-018-07034-4

4. MacDonald NE. Vaccine hesitancy: definition, scope and determinants. Vaccine. 2015;33(34):4161-4164. doi:10.1016/j. vaccine.2015.04.036

5. Peretti-Watel P, Larson HJ, Ward JK, Schulz WS, Verger P. Vaccine hesitancy: clarifying a theoretical framework for an ambiguous notion. PLoS Curr. 2015;1:7.

6. Dubé E, Vivion M, MacDonald NE. Vaccine hesitancy, vaccine refusal and the anti-vaccine movement: influence, impact and implications. Expert Rev Vaccines. 2015;14(1):99-117. doi:10.1586/14760584.2015.964212

7. Jarrett C, Wilson R, O'Leary M, Eckersberger E, Larson HJ. Strategies for addressing vaccine hesitancy - a systematic review. Vaccine. 2015;33(34):4180-4190. doi:10.1016/j.vaccine.2015.04.040

8. Leask J. Target the fence-sitters. Nature. 2011;473 (7348):443-445. doi:10.1038/473443a

9. Betsch C, Schmid P, Heinemeier D, Korn L, Holtmann C, Böhm R. Beyond confidence: development of a measure assessing the 5C psychological antecedents of vaccination. PLoS One. 2018;13(12):e0208601. doi:10.1371/journal.pone.0208601

10. Kuhn SAK, Lieb R, Freeman D, Andreou C, ZanderSchellenberg T. Coronavirus conspiracy beliefs in the German-speaking general population: endorsement rates and links to reasoning biases and paranoia. Psychol Med. 2021;1-15. doi:10.1017/S0033291721001124

11. Islam MS, Sarkar T, Khan SH, et al. COVID-19-related infodemic and its impact on public health: a global social media analysis. Am J Trop Med Hyg. 2020;103(4):1621-1629. doi:10.4269/ajtmh.20-0812

12. Depoux A, Martin S, Karafillakis E, Preet R, Wilder-Smith A, Larson $\mathrm{H}$. The pandemic of social media panic travels faster than the COVID-19 outbreak. J Travel Med. 2020;27(3). doi:10.1093/jtm/ taaa031 
13. Sallam M, Dababseh D, Yaseen A, et al. COVID-19 misinformation: mere harmless delusions or much more? A knowledge and attitude cross-sectional study among the general public residing in Jordan. PLoS One. 2020;15(12):e0243264. doi:10.1371/journal. pone. 0243264

14. Umakanthan S, Sahu P, Ranade AV, et al. Origin, transmission, diagnosis and management of coronavirus disease 2019 (COVID-19). Postgrad Med J. 2020;96(1142):753-758. doi:10.1136/postgradmedj-2020-138234

15. Umakanthan S, Chattu VK, Ranade AV, Das D, Basavarajegowda A, Bukelo M. A rapid review of recent advances in diagnosis, treatment and vaccination for COVID-19. AIMS Public Health. 2021;8 (1):137-153. doi:10.3934/publichealth.2021011

16. Machingaidze S, Wiysonge CS. Understanding COVID-19 vaccine hesitancy. Nat Med. 2021;27(8):1338-1339. doi:10.1038/ s41591-021-01459-7

17. Hasan T, Beardsley J, Marais BJ, Nguyen TA, Fox GJ. The Implementation of Mass-Vaccination against SARS-CoV-2: a Systematic Review of Existing Strategies and Guidelines. Vaccines. 2021;9(4):326. doi:10.3390/vaccines9040326

18. Heinz FX, Stiasny K. Distinguishing features of current COVID-19 vaccines: knowns and unknowns of antigen presentation and modes of action. NPJ Vaccines. 2021;6(1):104. doi:10.1038/s41541-021-00369-6

19. Rossman H, Shilo S, Meir T, Gorfine M, Shalit U, Segal E. COVID-19 dynamics after a national immunization program in Israel. Nat Med. 2021;27(6):1055-1061. doi:10.1038/s41591021-01337-2

20. Lopez Bernal J, Andrews N, Gower C, et al. Effectiveness of the Pfizer-BioNTech and Oxford-AstraZeneca vaccines on covid-19 related symptoms, hospital admissions, and mortality in older adults in England: test negative case-control study. $B M J$. 2021;373:n1088. doi:10.1136/bmj.n1088

21. Francis AI, Ghany S, Gilkes T, Umakanthan S. Review of COVID-19 vaccine subtypes, efficacy and geographical distributions. Postgrad Med J. 2021. doi:10.1136/postgradmedj-2021-140654

22. So AD, Woo J. Reserving coronavirus disease 2019 vaccines for global access: cross sectional analysis. BMJ. 2020;371:m4750m4750. doi:10.1136/bmj.m4750

23. Dyson L, Hill EM, Moore S, et al. Possible future waves of SARS-CoV-2 infection generated by variants of concern with a range of characteristics. Nat Commun. 2021;12(1):5730. doi:10.1038/s41467-021-25915-7

24. Forman R, Shah S, Jeurissen P, Jit M, Mossialos E. COVID-19 vaccine challenges: what have we learned so far and what remains to be done? Health Policy (New York). 2021;125(5):553-567. doi:10.1016/j.healthpol.2021.03.013

25. Sallam M. COVID-19 vaccine hesitancy worldwide: a concise systematic review of vaccine acceptance rates. Vaccines. 2021;9 (2). doi:10.3390/vaccines 9020160

26. Oyekale AS. Willingness to take COVID-19 vaccines in Ethiopia: an instrumental variable probit approach. Int J Environ Res Public Health. 2021;18(17). doi:10.3390/ijerph18178892

27. Abebe H, Shitu S, Mose A. Understanding of COVID-19 vaccine knowledge, attitude, acceptance, and determinates of COVID-19 vaccine acceptance among adult population in Ethiopia. Infect Drug Resist. 2021;14:2015-2025. doi:10.2147/idr.s312116

28. Mesele M. COVID-19 Vaccination acceptance and its associated factors in Sodo Town, Wolaita Zone, Southern Ethiopia: cross-sectional study. Infect Drug Resist. 2021;14:2361-2367. doi:10.2147/idr.s320771

29. Angelo AT, Alemayehu DS, Dachew AM. Health care workers intention to accept COVID-19 vaccine and associated factors in southwestern Ethiopia, 2021. PLoS One. 2021;16(9):e257109. doi:10.1371/journal.pone.0257109
30. Africa CDC. COVID-19 vaccine perceptions: a 15-country study. CDC Africa COVID-19 Vaccine Perceptions 2020; 2021. Available from: https://africacdc.org/download/covid-19-vaccineperceptions-a-15-country-study/. Accessed December 22, 2021.

31. Orangi S, Pinchoff J, Mwanga D, et al. Assessing the level and determinants of COVID-19 vaccine confidence in Kenya. Vaccines. 2021;9(8):Aug. doi:10.3390/vaccines9080936

32. Kanyanda S, Markhof Y, Wollburg P, Zezza A. The acceptance of covid-19 vaccines in Sub-Saharan Africa: evidence from 6 national phone surveys. medRxiv. 2021. doi:10.1101/ 2021.06.28.21259320

33. Dula J, Mulhanga A, Nhanombe A, et al. COVID-19 vaccine acceptability and its determinants in Mozambique: an online survey. Vaccines. 2021;9(8):828. doi:10.3390/vaccines 9080828

34. Solís Arce JS, Warren SS, Meriggi NF, et al. COVID-19 vaccine acceptance and hesitancy in low- and middle-income countries. Nat Med. 2021;27(8):1385-1394. doi:10.1038/s41591-02101454-y

35. Lazarus JV, Wyka K, Rauh L, et al. Hesitant or not? The association of age, gender, and education with potential acceptance of a COVID-19 vaccine: a country-level analysis. J Health Commun. 2020;25(10):799-807. doi:10.1080/10810730.2020.1868630

36. Adeniyi OV, Stead D, Singata-Madliki M, et al. Acceptance of COVID-19 vaccine among the healthcare workers in the Eastern Cape, South Africa: a cross sectional study. Vaccines. 2021;9 (6):666. doi:10.3390/vaccines9060666

37. Carcelen AC, Prosperi C, Mutembo S, et al. COVID-19 vaccine hesitancy in Zambia: a glimpse at the possible challenges ahead for COVID-19 vaccination rollout in sub-Saharan Africa. Hum Vaccin Immunother. 2021:1-6. doi:10.1080/ 21645515.2021.1948784.

38. Steward M, Moses M, Johanna Catharina M, et al. Awareness and acceptance of COVID-19 vaccines among pharmacy students in Zambia: the implications for addressing vaccine hesitancy. Research Square. 2021. doi:10.21203/rs.3.rs-651501/v1

39. Mundagowa PT, Tozivepi SN, Chiyaka ET, Mukora-Mutseyekwa F, Makurumidze R. Assessment of COVID-19 vaccine hesitancy among Zimbabweans: a rapid national survey. medRxiv. 2021. doi:10.1101/2021.06.24.21259505

40. Seydou A, Who wants COVID-19 vaccination? In 5 West African countries, hesitancy is high, trust low. Afrobarometer Dispatch No. 432 2021. Available from: https://afrobarometer.org/sites/ default/files/publications/Dispatches/ad432-covid-19_vaccine_hes itancy_high_trust_low_in_west_africa-afrobarometer-8march 21 . pdf. Accessed December 22, 2021.

41. Dinga JN, Sinda LK, Titanji VPK. Assessment of vaccine hesitancy to a COVID-19 vaccine in Cameroonian adults and its global implication. Vaccines. 2021;9(2):175. doi:10.3390/ vaccines 9020175

42. Ditekemena JD, Nkamba DM, Mutwadi A, et al. COVID-19 vaccine acceptance in the Democratic Republic of Congo: a cross-sectional survey. Vaccines. 2021;9(2):153. doi:10.3390/ vaccines 9020153

43. Lamptey E, Serwaa D, Appiah AB. A nationwide survey of the potential acceptance and determinants of COVID-19 vaccines in Ghana. Clin Exp Vaccine Res. 2021;10(2):183-190. doi:10.7774/ cevr.2021.10.2.183

44. Acheampong T, Akorsikumah EA, Osae-Kwapong J, Khalid M, Appiah A, Amuasi JH. Examining vaccine hesitancy in sub-Saharan Africa: a survey of the knowledge and attitudes among adults to receive COVID-19 vaccines in Ghana. Vaccines. 2021;9(8):814. doi:10.3390/vaccines9080814

45. Adejumo OA, Ogundele OA, Madubuko CR, et al. Perceptions of the COVID-19 vaccine and willingness to receive vaccination among health workers in Nigeria. Osong Public Health Res Perspect. 2021;12(4):236-243. doi:10.24171/j.phrp.2021.0023 
46. Josiah BO, Kantaris M. Perception of Covid-19 and acceptance of vaccination in Delta State Nigeria. Nigerian Health J. 2021;5:60-86.

47. Nemat A, Bahez A, Salih M, et al. Public willingness and hesitancy to take the COVID-19 vaccine in Afghanistan. Am J Trop Med Hyg. 2021;105(3):713-717. doi:10.4269/ajtmh.210231

48. Edwards B, Biddle N, Gray M, Sollis K, Di Gennaro F. COVID19 vaccine hesitancy and resistance: correlates in a nationally representative longitudinal survey of the Australian population. PLoS One. 2021;16(3):e0248892-e0248892. doi:10.1371/journal. pone. 0248892

49. Trent M, Seale H, Chughtai AA, Salmon D, MacIntyre CR. Trust in government, intention to vaccinate and COVID-19 vaccine hesitancy: a comparative survey of five large cities in the United States, United Kingdom, and Australia. Vaccine. 2021. doi:10.1016/j.vaccine.2021.06.048

50. Rhodes A, Hoq M, Measey M-A, Danchin M. Intention to vaccinate against COVID-19 in Australia. Lancet Infect Dis. 2021;21 (5):e110-e110. doi:10.1016/S1473-3099(20)30724-6

51. Dodd RH, Cvejic E, Bonner C, Pickles K, McCaffery KJ. Sydney Health Literacy Lab C-g. Willingness to vaccinate against COVID-19 in Australia. Lancet Infect Dis. 2021;21(3):318-319. doi:10.1016/S1473-3099(20)30559-4

52. Mahmud S, Mohsin M, Khan IA, Mian AU, Zaman MA. Knowledge, beliefs, attitudes and perceived risk about COVID-19 vaccine and determinants of COVID-19 vaccine acceptance in Bangladesh. PLoS One. 2021;16(9):e0257096. doi:10.1371/journal.pone.0257096

53. Ali M, Hossain A. What is the extent of COVID-19 vaccine hesitancy in Bangladesh? A cross-sectional rapid national survey. BMJ Open. 2021;11(8):e050303. doi:10.1136/bmjopen-2021-050303

54. Paul A, Sikdar D, Mahanta J, et al. Peoples' understanding, acceptance, and perceived challenges of vaccination against COVID-19: a cross-sectional study in Bangladesh. PLoS One. 2021;16(8):e0256493. doi:10.1371/journal.pone.0256493

55. Alam A, Azim Majumder MA, Haque M, et al. Disproportionate COVID-19 vaccine acceptance rate among healthcare professionals on the eve of nationwide vaccine distribution in Bangladesh. Expert Rev Vaccines. 2021;20(9):1167-1175. doi:10.1080/14760584.2021.1951248

56. Wang M-W, Wen W, Wang N, et al. COVID-19 vaccination acceptance among healthcare workers and non-healthcare workers in China: a survey. Front Public Health. 2021;9:709056. doi:10.3389/fpubh.2021.709056

57. Liu T, He Z, Huang J, et al. A Comparison of vaccine hesitancy of COVID-19 vaccination in China and the United States. Vaccines. 2021;9(6):649. doi:10.3390/vaccines9060649

58. Wang C, Han B, Zhao T, et al. Vaccination willingness, vaccine hesitancy, and estimated coverage at the first round of COVID-19 vaccination in China: a national cross-sectional study. Vaccine. 2021;39(21):2833-2842. doi:10.1016/j.vaccine.2021.04.020

59. Yan E, Lai DWL, Lee VWP. Predictors of intention to vaccinate against COVID-19 in the general public in Hong Kong: findings from a population-based, cross-sectional survey. Vaccines. 2021;9 (7). doi:10.3390/vaccines9070696

60. Wang K, Wong EL-Y, Ho K-F, et al. Change of willingness to accept COVID-19 vaccine and reasons of vaccine hesitancy of working people at different waves of local epidemic in Hong Kong, China: repeated cross-sectional surveys. Vaccines. 2021;9(1):62. doi:10.3390/vaccines9010062

61. Jacob J, Stephen S, Issac A, et al. Determinants of willingness for COVID-19 vaccine: implications for Enhancing the proportion of vaccination among Indians. Cureus. 2021;13(5):e15271-e15271. doi: $10.7759 /$ cureus. 15271
62. Kumari A, Ranjan P, Chopra S, et al. Knowledge, barriers and facilitators regarding COVID-19 vaccine and vaccination programme among the general population: a cross-sectional survey from one thousand two hundred and forty-nine participants. Diabetes Metab Syndr. 2021;15(3):987-992. doi:10.1016/j. dsx.2021.04.015

63. Singhania N, Kathiravan S, Pannu AK. Acceptance of coronavirus disease 2019 vaccine among health-care personnel in India: a cross-sectional survey during the initial phase of vaccination. Clin Microbiol Infect. 2021;27(7):1064-1066. doi:10.1016/j. cmi.2021.03.008

64. Harapan H, Wagner AL, Yufika A, et al. Acceptance of a COVID-19 vaccine in Southeast Asia: a cross-sectional study in Indonesia. Front Public Health. 2020;8:381. doi:10.3389/ fpubh.2020.00381

65. Triwardani R. Indonesian officials and media fight vaccine hesitancy, misinformation. Asian Politics Policy. 2021. doi:10.1111/ aspp. 12608

66. Wirawan GBS, Mahardani P, Cahyani MRK, Laksmi N, Januraga PP. Conspiracy beliefs and trust as determinants of COVID-19 vaccine acceptance in Bali, Indonesia: cross-sectional study. Pers Individ Dif. 2021;180:110995. doi:10.1016/j.paid.2021.110995

67. Nomura S, Eguchi A, Yoneoka D, et al. Reasons for being unsure or unwilling regarding intention to take COVID-19 vaccine among Japanese people: a large cross-sectional national survey. Lancet Reg Health West Pac. 2021:14. doi:10.1016/j.lanwpc.2021.100223.

68. Yoda T, Katsuyama H. Willingness to receive COVID-19 vaccination in Japan. Vaccines. 2021;9(1). doi:10.3390/ vaccines 9010048

69. Machida M, Nakamura I, Kojima T, et al. Acceptance of a COVID-19 vaccine in Japan during the COVID-19 pandemic. Vaccines. 2021;9(3). doi:10.3390/vaccines9030210

70. Kadoya Y, Watanapongvanich S, Yuktadatta P, Putthinun P, Lartey ST, Khan MSR. Willing or Hesitant? A socioeconomic study on the potential acceptance of COVID-19 vaccine in Japan. Int J Environ Res Public Health. 2021;18(9):4864. doi:10.3390/ ijerph18094864

71. Mohamed NA, Solehan HM, Mohd Rani MD, Ithnin M, Che Isahak CI. Knowledge, acceptance and perception on COVID-19 vaccine among Malaysians: a web-based survey. PLoS One. 2021;16(8):e0256110. doi:10.1371/journal. pone. 0256110

72. Syed Alwi SAR, Rafidah E, Zurraini A, Juslina O, Brohi IB, Lukas S. A survey on COVID-19 vaccine acceptance and concern among Malaysians. BMC Public Health. 2021;21(1):1129. doi:10.1186/s12889-021-11071-6

73. Thaker J. The persistence of vaccine hesitancy: COVID-19 vaccination intention in New Zealand. J Health Commun. 2021;26 (2):104-111. doi:10.1080/10810730.2021.1899346

74. Prickett KC, Habibi H, Carr PA. COVID-19 vaccine hesitancy and acceptance in a cohort of diverse New Zealanders. Lancet Reg Health West Pac. 2021;14:100241. doi:10.1016/j. lanwpc.2021.100241

75. Yasmin F, Asghar W, Babar MS, et al. Acceptance rates and beliefs toward COVID-19 vaccination among the general population of Pakistan: a cross-sectional survey. Am J Trop Med Hyg. 2021. doi:10.4269/ajtmh.21-0297

76. Tahir MJ, Saqlain M, Tariq W, et al. Population preferences and attitudes towards COVID-19 vaccination: a cross-sectional study from Pakistan. BMC Public Health. 2021;21(1):1759. doi:10.1186/s12889-021-11814-5

77. Malik A, Malik J, Ishaq U. Acceptance of COVID-19 vaccine in Pakistan among health care workers. PLoS One. 2021;16(9): e0257237. doi:10.1371/journal.pone.0257237 
78. Caple A, Dimaano AO, Sagolili MMC, et al. Interrogating COVID-19 vaccine hesitancy in the Philippines with a nationwide open-access online survey. medRxiv. 2021. doi:10.1101/2021.09.11.21263428

79. Choi SH, Jo YH, Jo KJ, Park SE. Pediatric and parents' attitudes towards COVID-19 vaccines and intention to vaccinate for children. J Korean Med Sci. 2021;36(31):e227. doi:10.3346/jkms.2021.36.e227

80. de Figueiredo A, Larson HJ. Exploratory study of the global intent to accept COVID-19 vaccinations. Commun Med. 2021;1 (1):30. doi:10.1038/s43856-021-00027-x

81. Tsai F-J, Yang H-W, Lin C-P, Liu JZ. Acceptability of COVID-19 vaccines and protective behavior among adults in Taiwan: associations between risk perception and willingness to vaccinate against COVID-19. Int J Environ Res Public Health. 2021;18 (11):5579. doi:10.3390/ijerph18115579

82. Khuc QV, Nguyen T, Nguyen T, et al. Young adults' intentions and rationales for COVID-19 vaccination participation: evidence from a student survey in Ho Chi Minh City, Vietnam. Vaccines. 2021;9(7):794. doi:10.3390/vaccines9070794

83. Patelarou A, Saliaj A, Galanis P, et al. Predictors of nurses' intention to accept COVID-19 vaccination: a cross-sectional study in five European countries. J Clin Nurs. 2021.

84. Patelarou E, Galanis P, Mechili EA, et al. Factors influencing nursing students' intention to accept COVID-19 vaccination: a pooled analysis of seven European countries. Nurse Educ Today. 2021;104:105010. doi:10.1016/j.nedt.2021.105010

85. Issanov A, Akhmetzhanova Z, Riethmacher D, Aljofan M. Knowledge, attitude, and practice toward COVID-19 vaccination in Kazakhstan: a cross-sectional study. Hum Vaccin Immunother. 2021;17(10):3394-3400. doi:10.1080/21645515.2021.1925054

86. Zhumaliev A. New joint MOH and WHO survey: $55 \%$ of the Kyrgyz population express strong or some willingness to get vaccinated; 2021. Available from: https://kyrgyzstan.un.org/en/124037-new-joint -moh-and-who-survey-55-kyrgyz-population-express-strong-or-some -willingness-get. Accessed December 22, 2021.

87. Ipsos. Attitudes of the citizens of Montenegro towards coronavirus: this opinion poll was conducted by Ipsos and supported by European Union and UNICEF Montenegro; 2021. Available from: https://www.unicef.org/montenegro/sites/unicef.org.monte negro/files/2021-09/IPSOS\%20July\%202021\%20ENG_\% 20Opsta\%20populacija_ENG.pdf. Accessed December 22, 2021.

88. Tran VD, Pak TV, Gribkova EI, et al. Determinants of COVID-19 vaccine acceptance in a high infection-rate country: a cross-sectional study in Russia. Pharm Pract (Granada). 2021;19(1):2276. doi:10.18549/PharmPract.2021.1.2276

89. Lazarus JV, Ratzan SC, Palayew A, et al. A global survey of potential acceptance of a COVID-19 vaccine. Nat Med. 2021;27 (2):225-228. doi:10.1038/s41591-020-1124-9

90. Matiashova L, Isayeva G, Shanker A, et al. COVID-19 vaccination in Ukraine: an update on the status of vaccination and the challenges at hand. $J$ Med Virol. 2021;93(9):5252-5253. doi:10.1002/jmv.27091

91. Giles-Vernick T, Vray M, Heyerdahl L, et al. Public views of COVID-19 vaccination in seven European Countries: options for response; 2021. Available from: https://www.recover-europe.eu/ wp-content/uploads/2021/02/Social-science-policy-brief_Vacci nation_v5.pdf. Accessed December 22, 2021.

92. Urrunaga-Pastor D, Bendezu-Quispe G, Herrera-Añazco P, et al. Cross-sectional analysis of COVID-19 vaccine intention, perceptions and hesitancy across Latin America and the Caribbean. Travel Med Infect Dis. 2021;41:102059. doi:10.1016/j.tmaid.2021.102059

93. Kothari A, Pfuhl G, Schieferdecker D, et al. The barrier to vaccination is not vaccine hesitancy: patterns of COVID-19 vaccine acceptance over the course of the pandemic in 23 countries. medRxiv. 2021. doi:10.1101/2021.04.23.21253857
94. Gramacho WG, Turgeon M. When politics collides with public health: COVID-19 vaccine country of origin and vaccination acceptance in Brazil. Vaccine. 2021;39(19):2608-2612. doi:10.1016/j.vaccine.2021.03.080

95. Kacimi SEO, Klouche-Djedid SN, Riffi O, et al. Determinants of SARS-CoV-2 vaccine engagement in Algeria: a population-based study with systematic review of studies from Arab countries of the MENA region. medRxiv. 2021. doi:10.1101/ 2021.07.17.21260662

96. Qunaibi EA, Helmy M, Basheti I, Sultan I. A high rate of COVID-19 vaccine hesitancy in a large-scale survey on Arabs. eLife. 2021;10. doi:10.7554/eLife.68038

97. Elgendy MO, Abdelrahim MEA. Public awareness about coronavirus vaccine, vaccine acceptance, and hesitancy. J Med Virol. 2021. doi:10.1002/jmv.27199

98. Fares S, Elmnyer MM, Mohamed SS, Elsayed R. COVID-19 vaccination perception and attitude among healthcare workers in Egypt. J Prim Care Community Health. 2021;12:21501327211013303. doi: $10.1177 / 21501327211013303$

99. El-Sokkary RH, El Seifi OS, Hassan HM, et al. Predictors of COVID-19 vaccine hesitancy among Egyptian healthcare workers: a cross-sectional study. BMC Infect Dis. 2021;21(1):762. doi:10.1186/s12879-021-06392-1

100. Omar DI, Hani BM. Attitudes and intentions towards COVID-19 vaccines and associated factors among Egyptian adults. $J$ Infect Public Health. 2021;341(1821):185. doi:10.1016/j.jiph.2021. 06.019

101. Koorosh K, Zarrintag H, Khadijeh H, et al. Determinants of COVID-19 vaccine acceptance in healthcare workers in Iran: national survey. Res Square. 2021. doi:10.21203/rs.3.rs923059/v1

102. Dror AA, Eisenbach N, Taiber S, et al. Vaccine hesitancy: the next challenge in the fight against COVID-19. Eur J Epidemiol. 2020;35(8):775-779. doi:10.1007/s10654-020-00671-y

103. El-Elimat T, AbuAlSamen MM, Almomani BA, Al-Sawalha NA, Alali FQ. Acceptance and attitudes toward COVID-19 vaccines: a cross-sectional study from Jordan. PLoS One. 2021;16(4): e0250555. doi:10.1371/journal.pone.0250555

104. Sallam M, Dababseh D, Eid H, et al. High rates of COVID-19 vaccine hesitancy and its association with conspiracy beliefs: a study in Jordan and Kuwait among other Arab countries. Vaccines. 2021;9(1):42. doi:10.3390/vaccines 9010042

105. Sallam M, Dababseh D, Eid H, et al. Low COVID-19 vaccine acceptance is correlated with conspiracy beliefs among university students in Jordan. Int J Environ Res Public Health. 2021;18 (5):2407. doi:10.3390/ijerph18052407

106. Alibrahim J, Awad A. COVID-19 vaccine hesitancy among the public in Kuwait: a cross-sectional survey. Int $J$ Environ Res Public Health. 2021;18(16):8836. doi:10.3390/ijerph18168836

107. Al-Sanafi M, Sallam M. Psychological determinants of COVID-19 vaccine acceptance among healthcare workers in Kuwait: a cross-sectional study using the $5 \mathrm{C}$ and Vaccine Conspiracy Beliefs Scales. Vaccines. 2021;9(7):701. doi:10.3390/vaccines 9070701

108. Kasrine Al Halabi C, Obeid S, Sacre H, et al. Attitudes of Lebanese adults regarding COVID-19 vaccination. BMC Public Health. 2021;21(1):998. doi:10.1186/s12889-021-10902-w.

109. Elhadi M, Alsoufi A, Alhadi A, et al. Knowledge, attitude, and acceptance of healthcare workers and the public regarding the COVID-19 vaccine: a cross-sectional study. BMC Public Health. 2021;21(1):955. doi:10.1186/s12889-021-10987-3

110. Al-Marshoudi S, Al-Balushi H, Al-Wahaibi A, et al. Knowledge, Attitudes, and Practices (KAP) toward the COVID-19 vaccine in Oman: a pre-campaign cross-sectional study. Vaccines. 2021;9 (6):602. doi:10.3390/vaccines 9060602 
111. Maraqa B, Nazzal Z, Rabi R, Sarhan N, Al-Shakhra K, Al-Kaila M. COVID-19 vaccine hesitancy among health care workers in Palestine: a call for action. Prev Med. 2021;149:106618. doi:10.1016/j.ypmed.2021.106618

112. Khaled SM, Petcu C, Bader L, et al. Prevalence and potential determinants of COVID-19 vaccine hesitancy and resistance in Qatar: results from a nationally representative survey of qatari nationals and migrants between December 2020 and January 2021. Vaccines. 2021;9(5):471. doi:10.3390/vaccines9050471

113. Al-Mansour K, Alyahya S, AbuGazalah F, Alabdulkareem K. Factors affecting COVID-19 vaccination among the general population in Saudi Arabia. Healthcare. 2021;9(9). doi:10.3390/ healthcare9091218

114. Alhofaian A, Tunsi A, Alaamri MM, et al. Perception of health care providers about COVID-19 and its vaccination in Saudi Arabia: cross-sectional study. $J$ Multidiscip Healthc. 2021;14:2557-2563. doi:10.2147/jmdh.s327376

115. Ahmed MAM, Colebunders R, Gele AA, et al. COVID-19 vaccine acceptability and adherence to preventive measures in Somalia: results of an online survey. Vaccines. 2021;9(6):543. doi:10.3390/vaccines 9060543

116. Amna K, Esra M, Mohammad N, et al. Acceptability of COVID-19 vaccination among healthcare workers in Sudan: a cross sectional survey. Research Square. 2021. doi:10.21203/ rs.3.rs-745232/v1

117. Mohamad O, Zamlout A, AlKhoury N, Mazloum AA, Alsalkini M, Shaaban R. Factors associated with the intention of Syrian adult population to accept COVID19 vaccination: a cross-sectional study. BMC Public Health. 2021;21(1):1310. doi:10.1186/s12889-021-11361-z

118. Salali GD, Uysal MS. COVID-19 vaccine hesitancy is associated with beliefs on the origin of the novel coronavirus in the UK and Turkey. Psychol Med. 2020;1-3. doi:10.1017/S0033291720004067

119. Kaplan AK, Sahin MK, Parildar H, Adadan Guvenc I. The willingness to accept the COVID-19 vaccine and affecting factors among healthcare professionals: a cross-sectional study in Turkey Int J Clin Pract. 2021;75(7):e14226. doi:10.1111/ijcp.14226

120. Albahri AH, Alnaqbi SA, Alshaali AO, Alnaqbi SA, Shahdoor SM. COVID-19 vaccine acceptance in a sample from the United Arab Emirates general adult population: a cross-sectional survey, 2020. Front Public Health. 2021;9:614499. doi:10.3389/fpubh.2021.614499

121. Bitar AN, Zawiah M, Al-Ashwal FY, et al. Misinformation, perceptions towards COVID-19 and willingness to be vaccinated: a population-based survey in Yemen. bioRxiv. 2021. doi:10.1101/ 2021.02.25.432838

122. King I, Heidler P, Marzo RR. The long and winding road: uptake, acceptability, and potential influencing factors of COVID-19 vaccination in Austria. Vaccines. 2021;9(7):790. doi:10.3390/ vaccines 9070790

123. Kessels R, Luyten J, Tubeuf S. Willingness to get vaccinated against Covid-19 and attitudes toward vaccination in general. Vaccine. 2021;39(33):4716-4722. doi:10.1016/j.vaccine.2021. 05.069

124. Janina S, Henrike S, Hannah P, et al. COVID-19 vaccine hesitancy in eight European countries: prevalence, determinants and heterogeneity. Res Square. 2021. doi:10.21203/rs.3.rs-840045/v1

125. Tang X, Gelband H, Nagelkerke N, et al. COVID-19 vaccination intention during early vaccine rollout in Canada: a nationwide online survey. Lancet Reg Health Am. 2021. doi:10.1016/j. lana.2021.100055

126. Raftopoulos V, Iordanou S, Katsapi A, Dedoukou X, Maltezou HC. A comparative online survey on the intention to get COVID-19 vaccine between Greek and Cypriot healthcare personnel: is the country a predictor? Hum Vaccin Immunother. 2021;17(8):2397-2404. doi:10.1080/21645515.2021.1896907
127. Riad A, Pokorná A, Antalová N, et al. Prevalence and Drivers of COVID-19 Vaccine Hesitancy among Czech University Students: national Cross-Sectional Study. Vaccines. 2021;9(9). doi:10.3390/ vaccines 9090948

128. Lindholt MF, Jørgensen F, Bor A, Petersen MB. Public acceptance of COVID-19 vaccines: cross-national evidence on levels and individual-level predictors using observational data. $B M J$ Open. 2021;11(6):e48172-e048172. doi:10.1136/bmjopen2020-048172

129. Hammer CC, Cristea V, Dub T, Sivelä J. Update on: high but slightly declining COVID-19 vaccine acceptance and reasons for vaccine acceptance, Finland April to December 2020. Epidemiol Infect. 2021;149:e187-e187. doi:10.1017/S0950268821001680

130. Schwarzinger M, Watson V, Arwidson P, Alla F, Luchini S. COVID-19 vaccine hesitancy in a representative working-age population in France: a survey experiment based on vaccine characteristics. Lancet Public Health. 2021;6(4):e210-e221. doi:10.1016/S2468-2667(21)00012-8

131. Alleaume C, Verger P, Dib F, Ward JK, Launay O, Peretti-Watel $P$. Intention to get vaccinated against COVID-19 among the general population in France: associated factors and gender disparities. Hum Vaccin Immunother. 2021;17(10):3421-3432. doi:10.1080/21645515.2021.1893069

132. Holzmann-Littig C, Braunisch MC, Kranke P, et al. COVID-19 vaccination acceptance and hesitancy among healthcare workers in Germany. Vaccines. 2021;9(7):777. doi:10.3390/ vaccines 9070777

133. Kourlaba G, Kourkouni E, Maistreli S, et al. Willingness of Greek general population to get a COVID-19 vaccine. Glob Health Res Policy. 2021;6(1):3. doi:10.1186/s41256-021-00188-1

134. Robertson DA, Mohr KS, Barjaková M, Lunn PD. A lack of perceived benefits and a gap in knowledge distinguish the vaccine hesitant from vaccine accepting during the COVID-19 pandemic. Psychol Med. 2021;1-4. doi:10.1017/S0033291721003743

135. Del Riccio M, Boccalini S, Rigon L, et al. Factors influencing SARS-CoV-2 vaccine acceptance and hesitancy in a population-based sample in Italy. Vaccines. 2021;9(6):633. doi:10.3390/vaccines 9060633

136. Neumann-Böhme S, Varghese NE, Sabat I, et al. Once we have it, will we use it? A European survey on willingness to be vaccinated against COVID-19. Eur $J$ Health Econ. 2020;21 (7):977-982. doi:10.1007/s10198-020-01208-6

137. Ebrahimi OV, Johnson MS, Ebling S, et al. Risk, trust, and flawed assumptions: vaccine hesitancy during the COVID-19 pandemic. Front Public Health. 2021;9:700213. doi:10.3389/ fpubh.2021.700213

138. Sowa P, Kiszkiel L, Laskowski PP, et al. COVID-19 vaccine hesitancy in Poland-multifactorial impact trajectories. Vaccines. 2021;9(8):876. doi:10.3390/vaccines9080876

139. Soares P, Rocha JV, Moniz M, et al. Factors associated with COVID-19 vaccine hesitancy. Vaccines. 2021;9(3):300. doi:10.3390/vaccines 9030300

140. Maftei A, Holman AC. SARS-CoV-2 threat perception and willingness to vaccinate: the mediating role of conspiracy beliefs. Front Psychol. 2021;12:672634. doi:10.3389/ fpsyg.2021.672634

141. Ştefănuţ AM, Vintilă M, Tomiţă M, Treglia E, Lungu MA, Tomassoni R. The influence of health beliefs, of resources, of vaccination history, and of health anxiety on intention to accept COVID-19 vaccination. Front Psychol. 2021;12:729803. doi:10.3389/fpsyg.2021.729803

142. Rodríguez-Blanco N, Montero-Navarro S, Botella-Rico JM, Felipe-Gómez AJ, Sánchez-Más J, Tuells J. Willingness to be vaccinated against COVID-19 in Spain before the start of vaccination: a cross-sectional study. Int $J$ Environ Res Public Health. 2021;18(10):5272. doi:10.3390/ijerph18105272 
143. Zürcher K, Mugglin C, Egger M, et al. Vaccination willingness for COVID-19 among health care workers in Switzerland. medRxiv. 2021. doi:10.1101/2021.07.04.21255203

144. Sherman SM, Smith LE, Sim J, et al. COVID-19 vaccination intention in the UK: results from the COVID-19 vaccination acceptability study (CoVAccS), a nationally representative cross-sectional survey. Hum Vaccin Immunother. 2021;17 (6):1612-1621. doi:10.1080/21645515.2020.1846397

145. Kerr JR, Schneider CR, Recchia G, et al. Correlates of intended COVID-19 vaccine acceptance across time and countries: results from a series of cross-sectional surveys. BMJ Open. 2021;11(8): e048025-e048025. doi:10.1136/bmjopen-2020-048025

146. Williams L, Flowers P, McLeod J, Young D, Rollins L, Team TCP. Social patterning and stability of intention to accept a COVID-19 vaccine in Scotland: will those most at risk accept a vaccine? Vaccines. 2021;9(1):17. doi:10.3390/vaccines9010017

147. Szilagyi PG, Thomas K, Shah MD, et al. National trends in the US Public's likelihood of getting a COVID-19 Vaccine-April 1 to December 8, 2020. JAMA. 2021;325(4):396-398. doi:10.1001/ jama.2020.26419

148. Mondal P, Sinharoy A, Su L. Sociodemographic predictors of COVID-19 vaccine acceptance: a nationwide US-based survey study. Public Health. 2021;198:252-259. doi:10.1016/j. puhe.2021.07.028

149. Khoury DS, Cromer D, Reynaldi A, et al. Neutralizing antibody levels are highly predictive of immune protection from symptomatic SARS-CoV-2 infection. Nat Med. 2021;27(7):1205-1211. doi:10.1038/s41591-021-01377-8

150. Naaber P, Tserel L, Kangro K, et al. Dynamics of antibody response to BNT162b2 vaccine after six months: a longitudinal prospective study. Lancet Reg Health Eur. 2021;10:100208. doi:10.1016/j.lanepe.2021.100208

151. Krause PR, Fleming TR, Longini IM, et al. SARS-CoV-2 variants and vaccines. $N$ Engl J Med. 2021;385(2):179-186. doi:10.1056/ NEJMsr2105280

152. Pegu A, O'Connell Sarah E, Schmidt stephen D, et al. Durability of mRNA-1273 vaccine-induced antibodies against SARS-CoV-2 variants. Science. 2021;373(6561):1372-1377. doi:10.1126/science. abj4176

153. Rella SA, Kulikova YA, Dermitzakis ET, Kondrashov FA. Rates of SARS-CoV-2 transmission and vaccination impact the fate of vaccine-resistant strains. Sci Rep. 2021;11(1):15729. doi:10.1038/ s41598-021-95025-3

154. Lazarevic I, Pravica V, Miljanovic D, Cupic M. Immune evasion of SARS-CoV-2 emerging variants: what have we learnt so far? Viruses. 2021;13(7):1192. doi:10.3390/v13071192

155. Patwary MM, Bardhan M, Disha AS, et al. Determinants of COVID-19 vaccine acceptance among the adult population of Bangladesh using the Health Belief Model and the Theory of Planned Behavior Model. Vaccines. 2021;9(12). doi:10.3390/ vaccines 9121393

156. Rosiello DF, Anwar S, Yufika A, et al. Acceptance of COVID-19 vaccination at different hypothetical efficacy and safety levels in ten countries in Asia, Africa, and South America. Narra J. 2021;1 (3):e55. doi:10.52225/narra.v1i3.55

157. Umakanthan S, Patil S, Subramaniam N, Sharma R. COVID-19 vaccine hesitancy and resistance in India explored through a population-based longitudinal survey. Vaccines. 2021;9(10). doi:10.3390/vaccines9101064

158. Obregon R, Mosquera M, Tomsa S, Chitnis K. Vaccine hesitancy and demand for immunization in Eastern Europe and Central Asia: implications for the region and beyond. $J$ Health Commun. 2020;25 (10):808-815. doi:10.1080/10810730.2021.1879366
159. Garcia PJ, Alarcón A, Bayer A, et al. COVID-19 response in Latin America. Am J Trop Med Hyg. 2020;103(5):1765-1772. doi:10.4269/ajtmh.20-0765

160. Umakanthan S, Chauhan A, Gupta MM, Sahu PK, Bukelo MM, Chattu VK. COVID-19 pandemic containment in the Caribbean Region: a review of case-management and public health strategies. AIMS Public Health. 2021;8(4):665-681. doi:10.3934/publichealth.2021053

161. Lohiniva AL, Barakat A, Dueger E, Restrepo S, El Aouad R. A qualitative study of vaccine acceptability and decision making among pregnant women in Morocco during the A (H1N1) pdm09 pandemic. PLoS One. 2014;9(10):e96244. doi:10.1371/journal. pone. 0096244

162. Our World in Data. Coronavirus (COVID-19) Vaccinations; 2021. Available from: https://ourworldindata.org/covid-vaccinations? country=OWID_WRL. Accessed December 22, 2021.

163. Suliman DM, Nawaz FA, Mohanan P, et al. UAE efforts in promoting COVID-19 vaccination and building vaccine confidence. Vaccine. 2021;39(43):6341-6345. doi:10.1016/j. vaccine.2021.09.015

164. Mollalo A, Tatar M. Spatial modeling of COVID-19 vaccine hesitancy in the United States. Int J Environ Res Public Health. 2021;18(18):9488. doi:10.3390/ijerph18189488

165. Polack FP, Thomas SJ, Kitchin N, et al. Safety and efficacy of the BNT162b2 mRNA Covid-19 vaccine. $N$ Engl J Med. 2020;383 (27):2603-2615. doi:10.1056/NEJMoa2034577

166. Voysey M, Clemens SAC, Madhi SA, et al. Safety and efficacy of the ChAdOx1 nCoV-19 vaccine (AZD1222) against SARS-CoV2: an interim analysis of four randomised controlled trials in Brazil, South Africa, and the UK. Lancet. 2021;397 (10269):99-111. doi:10.1016/S0140-6736(20)32661-1

167. Dubé E, Laberge C, Guay M, Bramadat P, Roy R, Bettinger J. Vaccine hesitancy: an overview. Hum Vaccin Immunother. 2013;9 (8):1763-1773. doi:10.4161/hv.24657

168. Dambadarjaa D, Altankhuyag G-E, Chandaga U, et al. Factors associated with COVID-19 vaccine hesitancy in Mongolia: a web-based cross-sectional survey. Int $J$ Environ Res Public Health. 2021;18(24):12903. doi:10.3390/ijerph182412903

169. Wijesekara N, Kodithuwakku K, Bulathsinghe B, Sachinthani J, Lakshani M. Eighty-six percent of Sri Lankans wish to receive COVID-19 Vaccine. Int $J$ Commun Resilience. 2021. doi:10.51595/11111116

170. Wang Q, Yang L, Jin H, Lin L. Vaccination against COVID-19: a systematic review and meta-analysis of acceptability and its predictors. Prev Med. 2021;150:106694. doi:10.1016/j. ypmed.2021.106694

171. Salomoni MG, Di Valerio Z, Gabrielli E, et al. Hesitant or not hesitant? A systematic review on global COVID-19 vaccine acceptance in different populations. Vaccines. 2021;9(8):873. doi:10.3390/vaccines 9080873

172. Nehal KR, Steendam LM, Campos Ponce M, van der Hoeven M, Smit GSA. Worldwide vaccination willingness for COVID-19: a systematic review and meta-analysis. Vaccines. 2021;9 (10):1071. doi:10.3390/vaccines9101071

173. Stojanovic J, Boucher VG, Gagne M, et al. Global trends and correlates of COVID-19 vaccination hesitancy: findings from the iCARE Study. Vaccines. 2021;9(6). doi:10.3390/vaccines9060661 


\section{Publish your work in this journal}

The Journal of Multidisciplinary Healthcare is an international, peerreviewed open-access journal that aims to represent and publish research in healthcare areas delivered by practitioners of different disciplines. This includes studies and reviews conducted by multidisciplinary teams as well as research which evaluates the results or conduct of such teams or healthcare processes in general. The journal

covers a very wide range of areas and welcomes submissions from practitioners at all levels, from all over the world. The manuscript management system is completely online and includes a very quick and fair peer-review system. Visit http://www.dovepress.com/testimonials. php to read real quotes from published authors. 